IZA DP No. 10395

Loss Aversion and Lying Behavior:

Theory, Estimation and Empirical Evidence

Ellen Garbarino

Robert Slonim

Marie Claire Villeval

November 2016 


\title{
Loss Aversion and Lying Behavior: Theory, Estimation and Empirical Evidence
}

\author{
Ellen Garbarino \\ University of Sydney \\ Robert Slonim \\ University of Sydney \\ and IZA
}

Marie Claire Villeval

University of Lyon, CNRS, GATE, IZA

and University of Innsbruck

\section{Discussion Paper No. 10395 \\ November 2016}

\author{
IZA \\ P.O. Box 7240 \\ 53072 Bonn \\ Germany \\ Phone: +49-228-3894-0 \\ Fax: +49-228-3894-180 \\ E-mail: iza@iza.org
}

Any opinions expressed here are those of the author(s) and not those of IZA. Research published in this series may include views on policy, but the institute itself takes no institutional policy positions. The IZA research network is committed to the IZA Guiding Principles of Research Integrity.

The Institute for the Study of Labor (IZA) in Bonn is a local and virtual international research center and a place of communication between science, politics and business. IZA is an independent nonprofit organization supported by Deutsche Post Foundation. The center is associated with the University of Bonn and offers a stimulating research environment through its international network, workshops and conferences, data service, project support, research visits and doctoral program. IZA engages in (i) original and internationally competitive research in all fields of labor economics, (ii) development of policy concepts, and (iii) dissemination of research results and concepts to the interested public.

IZA Discussion Papers often represent preliminary work and are circulated to encourage discussion. Citation of such a paper should account for its provisional character. A revised version may be available directly from the author. 


\section{ABSTRACT \\ Loss Aversion and Lying Behavior: Theory, Estimation and Empirical Evidence*}

We theoretically show that agents with loss-averse preferences facing a decision to receive a bad financial payoff if they report honestly or to receive a better financial payoff if they report dishonestly are more likely to lie to avoid receiving the low payoff the lower the ex-ante probability of the bad outcome. This occurs due to the ex-ante expected payoff increasing as the bad outcome becomes less likely, and hence the greater the loss that can be avoided by lying. We demonstrate robust support for this role of loss aversion on lying by reanalyzing the results from the extant literature covering 74 studies and 363 treatments, and from two new experiments that vary the outcome probabilities and examine lying for personal gain and for gains to causes one supports or opposes. To measure and compare lying behavior across treatments and studies, we develop an empirical method that estimates the full distribution of dishonesty when agents privately observe the outcome of a random process and can misreport what they observed.

JEL Classification: C91, C81, D03

Keywords: loss aversion, dishonesty, econometric estimation, experimental economics, lying

Corresponding author:

Marie Claire Villeval

CNRS, GATE Lyon St Etienne

93, Chemin des Mouilles

F-69130 Ecully

France

E-mail: villeval@gate.cnrs.fr

\footnotetext{
* We are grateful to J. van de Ven, S. Shalvi, C. de Dreu, and participants at the European Workshop of Experimental and Behavioral Economics in Cologne, the ESA world meeting in Jerusalem, the SITE conference at Stanford University, the ESA European meeting in Bergen, and at seminars at AixMarseille University, University of Amsterdam and at Turku University for thoughtful comments. Financial support from the University of Sydney and the FELIS program of the French National Agency for Research (ANR-14-CE28-0010-01) is gratefully acknowledged. This research was performed within the framework of the LABEX CORTEX (ANR-11-LABX-0042) of Universite de Lyon, within the program Investissements d'Avenir (ANR-11-IDEX-007) operated by the French National Research Agency (ANR). It has been initiated while R. Slonim was visiting GATE at Ecole Normale Supérieure de Lyon.
} 


\section{Introduction}

Dishonesty is pervasive and dramatically deters economic growth and development. ${ }^{1}$ Going beyond the economics-of-crime approach (Becker, 1968), economists have begun to intensely study the behavioral determinants of dishonesty. This emerging literature shows that the extent to which individuals are or are not willing to follow the moral course of action is affected by ethical values, social preferences, institutions, and norms (e.g., Gneezy, 2005; Ariely, 2012; Gächter and Schultz, 2016; Mann et al., 2016). ${ }^{2}$ Whereas the effect of the level of incentives (i.e., the financial benefit) and of the nature of incentives (e.g., individual, team-based or competitive) on dishonesty has received substantial attention, ${ }^{3}$ little is known theoretically or empirically about the impact of the probability of payoffs on dishonesty. ${ }^{4}$ This is surprising, as economists have intensively explored how individuals take actions to avoid unlikely low payoffs (e.g., by investing in effort, buying insurance or protection, etc.). If legal actions are taken for this purpose, it is likely that some individuals may also use dishonest actions with the same objective (e.g., exaggerating insurance claims in case of an accident, cheating to get a bonus, etc.). To fill this gap, our first two contributions are to theoretically and empirically study the role of payoff probabilities on dishonesty. Our third main contribution is to introduce an econometric method to estimate the full distribution of

\footnotetext{
${ }^{1}$ For example, the overall gross tax gap estimate by IRS in the U.S represents about $16 \%$ of estimated actual tax liability. The global hidden financial assets in offshore tax havens represent up to $\$ 280$ billion in lost income tax revenues. These unpaid taxes limit the resources available to invest in public services. The World Bank Institute estimates that corruption is equal to about $2 \%$ of global GDP. Corruption and embezzlement deter investment, and therefore hinder growth. ${ }^{2}$ For recent surveys on the experimental economic literature on dishonest behavior, see Rosenbaum et al. (2014), Irlenbusch and Villeval (2015), and Abeler et al. (2016).

${ }^{3}$ Studies examining the level of incentives include Fischbacher and Föllmi-Heusi (2013) and Kajackaite and Gneezy (2015). Studies examining the nature of incentives include Jacob and Levitt (2003), Conrads et al. (2013), Danilov et al. (2013), Charness et al. (2014) and Faravelli et al. (2015).

${ }^{4}$ A notable exception is the recent paper by Gneezy, Kajackaite and Sobel (2016). They show theoretically (and confirm experimentally, as does Abeler et al., 2016) that the level of dishonesty among individuals with reputation concerns can also be systematically affected by the probability of the outcomes. Our theoretical model explores a distinct and complementary avenue through loss aversion preferences for the effect of the outcome probabilities on dishonesty, and critically we design our experiments to exclude the possibility of reputation concerns affecting choice.
} 
dishonesty in the most common context used to study dishonesty: when agents privately observe the outcome of a random process but can report a different outcome.

Theoretically, we explore a determinant of dishonesty that is predicted by loss aversion and which operates through the probability of the privately observed outcomes that people can either report on honestly or dishonestly. Specifically, we show that loss aversion predicts that the extent to which individuals behave dishonestly is sensitive to the probability of observed outcomes because these probabilities affect the payoff that is expected to be observed, and the expected payoff in turn affects the loss-averse utility of the honest and dishonest reports. If individuals suffer more from losses than they enjoy equivalent gains, as loss aversion contends (Kahneman and Tversky, 1979; 1992), then individuals will gain more utility from being dishonest the further the realized outcome is below the payoff that they expected to observe. That is, the less likely a bad payoff outcome is expected to occur, the more this bad outcome will be below the expected outcome, and thus the greater the loss that is avoided by lying.

Only a few studies have experimentally investigated the role of loss aversion in cheating, but none theoretically. These studies manipulate the endowment to vary the reference state; in particular, subjects can receive from $\$ 0$ to $\$ \mathrm{X}$ with no endowment (the gain frame) or receive from $-\$ \mathrm{X}$ to $\$ 0$ plus an \$X endowment (the loss frame). They generally find support for greater dishonesty in the loss than gain frame. ${ }^{5}$ In contrast, we analyze the variation in the reference state resulting from differences in the probabilities of the privately observed outcomes. In our model, a dishonest report causes a gain in utility from the payoffs occurring in both the loss and gain domains, where variations in the probability of the outcomes affects the relative size of the gains and losses that

\footnotetext{
${ }^{5}$ For example, two studies using real-effort experimental tasks find that individuals misreport their performance more in a loss than in an equivalent gain frame (Cameron and Miller, 2013; Grolleau et al., 2016). Another study using both a die-rolling task and a coin-tossing task also find that more people cheat in a loss than gain frame (Schindler and Pfattheicher, 2016). In contrast, Blanco et al. (2015) find that people cheat in a gain frame, but not in a loss frame. In a different approach, Shalvi (2012) examines lying to affect the odds of winning and shows that individuals dishonestly increase the likelihood of wining by turning negative gambles into positive gambles.
} 
occur between reporting honestly and dishonestly. Hence, our model provides a formal theoretical relationship between loss aversion and lying.

Our second main contribution is empirical. We first test the theoretical implications of our model by re-examining the extensive experimental literature on dishonesty in which the outcome of a random draw that is observed only by the subject is reported to the experimenter. In this literature, the probabilities of the outcomes and the rate of lying vary dramatically across studies, allowing us to test the implications of our loss aversion model. We then further test the theoretical implications by conducting two new experiments in two distinct contexts that control for all factors other than the probabilities of the payoff outcomes that subjects can observe.

Empirically studying the likelihood that individuals cheat requires a valid statistical measure of dishonesty. Because statistics on fraud in natural settings focus on people who have been detected, which introduces a selection bias, researchers have increasingly turned to running experiments where subject populations include participants who might be more representative of the general population with regard to the likelihood to commit fraud. The most common technique to detect cheating involves subjects generating an outcome from a random device (e.g., flipping a coin, rolling a die, drawing a card) where the outcome can only be observed by the subject (e.g., Fischbacher and Föllmi-Heusi, 2013; Shalvi et al., 2011). If a subject privately observes an outcome with a payoff that is less than the maximum possible payoff, then he has a financial incentive to lie by dishonestly reporting a higher payoff outcome than observed. ${ }^{6}$

\footnotetext{
${ }^{6}$ The artificiality of the laboratory may, however, affect behavior. Reassuringly, the literature shows that dishonesty in the lab correlates with dishonesty in the field (Hanna and Wang, 2013; Barfort et al., 2015; Cohn and Maréchal, 2015; Cohn et al., 2015; Dai et al., 2016; Potters and Stoop, 2016). Moreover, several modifications have been tried to reduce the risk of scrutiny. For example, the die can be put in a cup to make more salient the fact that only the subject can observe the realization of the die roll (Shalvi et al., 2011). In "mind games," as used in this paper, subjects have to predict the realization of an outcome prior to acting and report whether their prediction was correct or wrong (Shalvi, 2012; Jiang, 2013; Barfort et al., 2015; Kajackaite and Gneezy, 2015; Potters and Stoop, 2016). This method guarantees to subjects that a lie can never be detected.
} 
Virtually every paper using this experimental technique compares the proportion of each reported outcome with the theoretical proportion if subjects truthfully reported what they observed. While this approach indicates whether the proportion of subjects reporting any particular outcome differs from the expected proportion if all subjects reported honestly, it does not describe the distribution of the proportion of subjects that behaved dishonestly. This limitation makes it difficult to compare the extent of lying across studies beyond indicators for when dishonesty does and does not significantly occur. ${ }^{7}$ This limitation motivates our econometric contribution, the provision of a technique to estimate the full distribution of the proportion of individuals who lie. By estimating the full distribution of dishonesty, our econometric technique provides a precise estimate not only of the mean and confidence intervals (indicating lower and upper bounds on the proportion of people reporting dishonestly), but also for any other statistical inference researchers want to use that can be inferred from the full distribution. The technique uses the information on the distribution of possible outcomes individuals can observe to infer the PDF and CDF of dishonesty. We have also developed a software to implement our technique that is freely available at the following address: ftp://ftp.gate.cnrs.fr/LyingCalculator/LyingCalculator.zip. In addition to allowing researchers to estimate the distribution of lying for their data, the calculator provides a trivial method to perform power calculations to determine appropriate sample sizes for each treatment.

We first apply our technique to empirically test our theory on the extant lying literature. We estimate the mean percent of individuals reporting dishonestly from all studies exploring lying using

\footnotetext{
${ }^{7}$ Abeler et al. (2016) advance the analysis by using a simple formula to report a proxy for the mean lying percent. Their formula indicates that the percent of subjects that lie equals $(r-p) /(1-p)$ where $r$ is the percentage of subjects that report the higher payoff and $p$ is the likelihood of observing this good outcome. For instance, in a coin toss $(p=50 \%)$, if $r=60 \%$, then this formula implies that on average $20 \%\{(0.6-0.5) / 0.5\}$ would have lied. There are, however, limitations to this formula. First, it does not provide the distribution, confidence intervals or any other statistic. Second, the statistic may not correctly measure the mean. This can most easily be seen if we look at when $r=50 \%$, in which case this formula indicates that on average $0 \%$ of subjects $\{(0.5-0.5) / 0.5\}$ would have lied. However, this ignores the distribution of possible outcomes that the subjects could have observed that includes less than $50 \%$ observing the higher payoff outcome who then report dishonestly. Our approach addresses these limitations by providing the entire CDF and PDF of lying including the correct mean of the distribution.
} 
random devices we were able to obtain data from. We started from the list of studies surveyed by Abeler et al. (2016) and added a few additional studies. Our review includes 74 studies representing 363 treatments and 33,540 individuals from 44 countries. ${ }^{8}$ Controlling for several variables that can affect the decision to lie (e.g., monetary stakes, laboratory setting, etc.), we find a highly significant and robust negative correlation, ranging from -0.36 to -0.66 depending on the specifications, between the probability of observing a low payoff outcome and the mean lying propensity. This betweenstudy correlation indicates, as predicted by loss aversion, that the mean proportion of individuals that behave dishonestly to avoid a low payoff outcome is higher when this outcome is less likely. ${ }^{9}$

While this evidence is consistent with the loss aversion hypothesis, an alternative theory could also potentially explain this pattern. Reputation concerns, as modeled in Gneezy et al. (2016) or in Dufwenberg and Dufwenberg (2016) predict an equilibrium in which individuals are more likely to lie to get a higher payoff the less likely the claim for a higher payoff will be perceived as lying by observers (e.g., the experimenter); reputation concerns therefore predict that a claim for the good outcome will be less likely to be perceived as a lie if the good outcome is more likely. Thus, both reputation concerns and loss aversion may be driving the relationship we observe in our analysis of the literature. To isolate and further test the loss aversion lying hypothesis, to avoid across experiment differences in the extant literature and to eliminate reputation concern effects, we designed two experiments using a "mind coin-tossing game" in which we vary the likelihood of the

\footnotetext{
${ }^{8}$ We include 69 of the 72 studies used by Abeler et al. (2016) and add five other studies. Importantly, the objectives of the two reviews are different: while Abeler et al. (2016) try to identify the individual, economic and methodological determinants of misreporting, we focus exclusively on the impact of the distribution of probabilities of the low and high outcomes on the mean lying rate, a dimension that they do not consider. Another difference is that while they conduct a meta-analysis at the level of individual decisions, our analysis is conducted at the treatment level.

${ }^{9}$ For example, subjects lie more in a die task where only one value earns zero payoff (like in Fischbacher and FöllmiHeusi (2013) in which the mean lying rate to avoid the zero payoff is 61\%) than when five out of six sides earn zero (like in Kajackaite and Gneezy (2016) in which the mean lying rate is only 15\%). Our results hold regardless of whether we define a bad payoff outcome as the lowest possible outcome or all outcomes except the highest one.
} 
various outcomes. Both experiments were run on-line and double-anonymous (i.e., with no chance of any observers) to remove reputation concerns.

In both experiments, individuals have to predict the outcome of a coin toss before tossing a coin in private. This task is repeated three times and then subjects have to report the number of correct predictions, which determines their payoff. Across subjects and in two substantially different contexts, we vary the number of correct predictions required to earn a fixed amount of money, which makes the probability of the undesired outcome (earning \$) vary from $12.5 \%$ to $50 \%$ to $87.5 \%$. In study one, involving 978 subjects on MTurk, the beneficiary of a lie is oneself and the subject can earn either $\$ 0$ or $\$ 2$. In study two, involving 422 different MTurkers, the beneficiary is a cause that the subject either supports or opposes, either the Democratic National Party or the Republican National Party in the U.S., and the subject can earn either $\$ 0, \$ 1$ or $\$ 8$ for the party they are randomly assigned to for the experiment. ${ }^{10}$

In our online experiments, designed to avoid reputation effects, we use our econometric approach to demonstrate that, consistent with our loss aversion prediction, people lie statistically more often to avoid the undesired outcome when the probability of this undesired outcome is lower. When the outcome of the task benefits the subject directly, on average $75.88 \%$ of the subjects $(95 \%$ Confidence Interval: $70.03 \%-80.62 \%$ ) lie to get a $\$ 2$ rather than $\$ 0$ payoff when the likelihood of getting the low payoff is $12.5 \%$, whereas $66.26 \%$ (CI: $62.40 \%-69.73 \%$ ) lie when the likelihood of the low payoff is $50 \%$ and only $44.18 \%$ (CI: $39.39 \%-48.63 \%$ ) lie when the likelihood is $87.5 \%$. The same qualitative finding is observed when the beneficiary of a lie is either a cause that the individual supports or a cause that he opposes. On average, $77.65 \%$ (CI: $63.59 \%-86.47 \%$ ) of subjects lie to avoid giving $\$ 0$ to a cause they support and 59.62\% (CI: $37.86 \%-74 \%$ ) lie to avoid giving the highest possible payoff $(\$ 8)$ to a cause they oppose when the likelihood of these outcomes is $12.5 \%$. The

\footnotetext{
${ }^{10}$ The studies were run in April 2016 during the primary season before either party's nominee had been determined.
} 
respective mean percentages decrease to $21.24 \%$ (CI: $6.43 \%-34.35 \%$ ) and $33.79 \%$ (CI: $22.13 \%$ $43.76 \%$ ) when the probability of those outcomes is $50 \%$, and further decreases to $7.61 \%$ (CI: $1.70 \%$ $13.69 \%$ ) of supporters that lie to give $\$ 8$ to their party and $4.25 \%(\mathrm{CI}: 0 \%-9.47 \%)$ of subjects that lie to give $\$ 0$ to the party they oppose when the likelihood of a bad outcome is $87.5 \%$.

Overall, we show that loss aversion predicts that the probability of observing each payoff outcome affects the level of dishonesty. Our review of the extant literature and our two experiments confirm that individuals are more likely to lie when the undesired outcome is more unlikely, and this follows theoretically from the implications of loss aversion.

The remainder of this paper is organized as follows. Section 2 presents the theory showing how the probability of the outcomes affects lying for people with loss averse preferences. Section 3 presents our econometric technique to estimate the distribution of the percentage of subjects who misreport. Section 4 applies this method to the existing literature while Section 5 presents our two new experiments. Section 6 discusses our results and concludes.

\section{A theory of Loss Aversion and the probability of outcomes on lying}

This section shows theoretically that agents with loss averse preferences who privately observe the low payoff outcome will be increasingly likely to lie the smaller the ex-ante probability of observing this low outcome. To show this, we examine the comparative static effect of changing the probability of observing the low payoff on the difference in the utility of dishonestly reporting the not-observed high payoff $v s$. honestly reporting the observed low payoff.

Let $x_{1}$ and $x_{2}\left(x_{2}>x_{1}\right)$ be an agent's monetary payoffs if he reports the low and high payoff outcomes, respectively, where the ex-ante probability of observing $x_{1}$ and $x_{2}$ is $p$ and $1-p$. In this context, the ex-ante expected observed payoff is $x_{\mathrm{e}}=p x_{1}+(1-p) x_{2}$; i.e., $\mathrm{x}_{\mathrm{e}}$ is the expected observed realization before observing how the random event is resolved. We show that if an agent has lossaverse preferences (Kahneman and Tversky, 1979; 1992) and uses the ex-ante expected observed 
payoff $x_{\mathrm{e}}$ as his reference point, then after observing the low payoff outcome he will be increasingly more likely to dishonestly report the high payoff than to honestly report the low payoff the less likely the ex-ante probability of observing the low payoff outcome (i.e., the smaller $p$ is). Intuitively, as the likelihood of observing the low payoff decreases, the ex-ante expected observed outcome (the reference point) increases, so the sense of loss related to honestly reporting a low payoff increases. As the probability of the low payoff decreases, the person expects an increasingly higher payoff and so increasingly suffers a greater loss if he reports the low payoff, and hence is more inclined to dishonestly report the higher outcome to avoid that loss. In other words, as the likelihood of observing the ex-ante low payoff decreases, the gain in utility for a loss-averse person who reports dishonestly to avoid the loss increases, thus increasing the benefits of a dishonest vs. honest report. We now formally show this.

We assume an agent's utility is a function of the moral cost of dishonesty and the referencedependent loss-averse utility of the monetary payoff:

$$
U\left(x_{R} \mid x_{O}\right)=g\left(x_{2}-x_{e}\right) * \mathrm{I}\left(x_{2} \geq x_{e}\right)-h\left(x_{e}-x_{1}\right) * \mathrm{I}\left(x_{1}<x_{e}\right)-m\left(x_{R}-x_{O}\right) * \mathrm{I}\left(x_{R} \neq x_{O}\right)
$$

where $\mathrm{I}()$ is an indicator function that equals 1 if true and 0 if false, and $x_{R}$ and $x_{O}$ are the agent's reported and privately observed outcomes, respectively. The functions $m(), g()$ and $h()$ are continuous and twice differentiable; $m()$ is the moral cost of reporting an outcome that was not observed, and $g()$ and $h()$ are the utility of gains and losses, respectively. We assume:

$$
m^{\prime}(x) \geq 0 \text { and } m^{\prime \prime}(x) \geq 0
$$

Assumption (2) reflects the (weakly) increasing moral cost of lying as a function of the gain from misreporting. For instance, Mazar et al. (2008), Lundquist et al. (2009), and Fischbacher and Föllmi-Heusi (2013) find evidence consistent with $m^{\prime}(x)>0$, while Kajackaite and Gneezy (2015) do not reject that $m^{\prime}(x)=0$. 
If the agent observes the low payoff outcome (i.e., $\left.x_{O}=x_{1}\right)$, then he has a monetary incentive to dishonestly report observing the higher payoff, $x_{R}=\mathrm{x}_{2}$. It follows from equation (1) that when observing the low payoff outcome, the agent's utility if he reports the low or high payoff, respectively, will be: ${ }^{11}$

$$
\begin{aligned}
& U\left(x_{1} \mid x_{1}\right)=-h\left(x_{e}-x_{1}\right) \\
& U\left(x_{2} \mid x_{1}\right)=g\left(x_{2}-x_{e}\right)-m\left(x_{2}-x_{O}\right)
\end{aligned}
$$

It follows that the difference in utility $U(d)$ between dishonestly reporting observing the high payoff $\left(x_{2}\right)$ and honestly reporting observing the low payoff $\left(x_{1}\right)$ is:

$$
U(d)=U\left(x_{2} \mid x_{1}\right)-U\left(x_{1} \mid x_{1}\right)=g\left(x_{2}-x_{\mathrm{e}}\right)+h\left(x_{\mathrm{e}}-x_{1}\right)-m\left(x_{2}-x_{1}\right)
$$

Equation 5 highlights how the utility gained by an agent with reference-dependent loss-averse preferences when reporting dishonestly $v s$. honestly can be decomposed into two components. First, he gains utility from the monetary gain above the reference point, $g\left(x_{2}-x_{\mathrm{e}}\right)$, and second, he gains utility from avoiding the monetary loss below the reference point $h\left(x_{\mathrm{e}}-x_{1}\right)$.

Substituting for $x_{e}=p x_{1}+(1-p) x_{2}$ and rearranging, the difference in utility $\mathrm{U}(d)$ between dishonestly reporting observing the high payoff $\left(x_{2}\right)$ and honestly reporting observing the low payoff $\left(x_{1}\right)$ is:

$$
U(d)=g\left(p^{*}\left(x_{2}-x_{1}\right)\right)+h\left((1-p) *\left(x_{2}-x_{1}\right)\right)-m\left(x_{2}-x_{1}\right)
$$

Differentiating $U(d)$ with respect to the probability of the low outcome $(p)$, we have:

$$
\begin{aligned}
U^{\prime}(d) & =\left(x_{2}-x_{1}\right)\left[g^{\prime}\left(p\left(x_{2}-x_{1}\right)\right)-h^{\prime}\left((1-p)\left(x_{2}-x_{1}\right)\right)\right], \text { and } \\
U^{\prime \prime}(d) & =\left(x_{2}-x_{1}\right)^{2}\left[g^{\prime \prime}\left(p\left(x_{2}-x_{1}\right)\right)+h^{\prime \prime}\left((1-p)\left(x_{2}-x_{1}\right)\right)\right]
\end{aligned}
$$

\footnotetext{
${ }^{11}$ Given our assumption that if an agent observes the high outcome, $x_{\mathrm{O}}=x_{2}$, then it is trivial to show that he will always receive higher utility honestly reporting the high payoff outcome $\left(x_{\mathrm{R}}=x_{2}\right.$, ) than dishonestly reporting the low payoff outcome $\left(x_{\mathrm{R}}=x_{1}\right)$. Among others, Houser et al. (2012), Fischbacher and Föllmi-Heusi (2013), Cohn et al. (2015), and Dai et al. (2016) acknowledge that downward lying may occur because of altruism towards the experimenter or because subjects fear of being identified as cheaters, but they assume that this behavior is extremely unlikely. In all of the 357 treatments we have examined, we have found only one treatment (Utikal and Fischbacher, 2013) in which subjects report the low payoff outcome statistically more often than the expected frequency of the true distribution they should have observed. This has been observed with a very specific population: nuns. Moreover, in their Observed treatments, Gneezy et al. (2016) have identified only one subject out of 602 who underreports. Thus, we do not theoretically examine the possibility of lying in the case where subjects observe the higher payoff outcome.
} 
To examine the effect of a change in $p$ on reporting honestly or dishonestly, we examine the two distinct forces driving the overall comparative static effect. First, we isolate the effect of loss aversion (i.e., the effect that for equivalently sized monetary losses and gains, losses have a larger effect on utility than gains) by assuming linear marginal utility over gains and losses. Second, we isolate the reference-dependent effect of diminishing marginal utility of losses and gains by assuming the utility of losses and gains are identical (i.e., $g(x)=h(x)$ ). These cases provide the intuition for the two forces on the impact of loss-averse reference-dependent preferences on reporting dishonestly rather than honestly as the probability of observing the bad outcome changes. After examining these two cases, we then examine the overall impact, assuming both loss aversion and reference dependence.

Case 1: Loss Aversion without reference-dependent diminishing marginal utility:

To isolate the loss aversion effect, we assume:

$$
\begin{aligned}
& g(x)=k x(k>0) \\
& h(x)=(1+a) g(x) \text { and } a>0 .
\end{aligned}
$$

$g(x)$ and $h(x)$ are linear utility functions (i.e., no diminishing marginal utility) and with $a>0 h(x)$ is steeper than $g(x)$, reflecting loss aversion. In this case, the marginal utility of reporting dishonestly $v s$. honestly is:

$$
U^{\prime}(d)=k\left(x_{2}-x_{1}\right)-(1+a) k\left(x_{2}-x_{1}\right)=-a k\left(x_{2}-x_{1}\right)<0
$$

Intuitively, as the probability of observing the bad payoff increases, the increase in utility in the gain domain, $k\left(x_{2}-x_{1}\right)$, is always less than the decrease in utility in the loss domain, $(1+a) k\left(x_{2}-x_{1}\right)$. This follows immediately from the steeper slope of losses than gains assumed with loss-averse preferences. Thus, as the probability of observing the bad payoff increases, the net gain in utility from the monetary payment falls, and may fall below the moral cost of lying, at which point the 
agent will have overall greater utility from reporting honestly. For a decrease in the probability of observing the bad payoff, therefore, we have our main result:

Theoretical Result 1 (Loss aversion effect on reporting dishonestly): As the probability of observing the bad payoff outcome decreases, increasing utility will be received from reporting dishonestly than honestly.

\section{Case 2: Reference-dependence and diminishing marginal utility without loss aversion:}

To isolate the reference-dependent diminishing marginal utility effect, we assume that (a) the utility of losses and gains are identical for the same absolute size of the gain and loss, and (b) the utility of gains and losses exhibit diminishing marginal utility the further payoffs are from the reference point:

$$
g(x)=h(x) \text { and } \quad g^{\prime}(x)>0 \text { and } g^{\prime \prime}(x)<0 .
$$

In this case, we have:

$$
\begin{aligned}
& U^{\prime}(d)=\left(x_{2}-x_{1}\right)\left[g^{\prime}\left(p\left(x_{2}-x_{1}\right)\right)-g^{\prime}\left((1-p)\left(x_{2}-x_{1}\right)\right)\right], \text { and } \\
& U^{\prime}(d)=\left(x_{2}-x_{1}\right)^{2}\left[g^{\prime}\left(p\left(x_{2}-x_{1}\right)\right)+g^{\prime \prime}\left((1-p)\left(x_{2}-x_{1}\right)\right)\right]
\end{aligned}
$$

Given diminishing marginal utility, $g^{\prime \prime}(x)<0$, it immediately follows that $\mathrm{U}^{\prime \prime}(d)<0$ for all $p$. Further, equation ( $\left.7^{\prime \prime}\right)$ indicates that if $p=0.5$ then $U^{\prime}(d)=\left(x_{2}-x_{1}\right)\left[g^{\prime}\left(.5\left(x_{2}-x_{1}\right)\right)-g^{\prime}\left(.5\left(x_{2}-x_{1}\right)\right)\right]=0$. Thus, given $\mathrm{U}^{\prime}(d)<0$ for all $p$ and $\mathrm{U}^{\prime}(d)=0$ when $p=0.5$, it immediately follows that:

$$
\begin{aligned}
& \text { For } p<0.5: \mathrm{U}^{\prime}(d)>0 ; \mathrm{U}^{\prime},(\mathrm{d})<0 \\
& \text { For } p=0.5: \mathrm{U}^{\prime}(d)=0 ; \mathrm{U}^{\prime}(\mathrm{d})<0 \\
& \text { For } p>0.5: \mathrm{U}^{\prime}(d)<0 ; \mathrm{U}^{\prime},(\mathrm{d})<0
\end{aligned}
$$

Intuitively, when $p$ is less than 0.5 , the reference point $x_{e}, x_{e}=p x_{1}+(1-p) x_{2}$, is closer to the higher payoff $x_{2}$ than the lower payoff $x_{1}$, i.e., $\left|x_{2}-x_{e}\right|=p\left(x_{2}-x_{1}\right)<\left|x_{1}-x_{e}\right|=(1-p)\left(x_{2}-x_{1}\right)$, and thus we are on the steeper part of the utility function in the domain of gains than in the domain of losses due to the assumed diminishing marginal utility; thus, as $p$ increases, more utility is gained in the gain domain than is lost in the loss domain, and thus $U^{\prime}(d)>0$. In contrast, when $p$ is greater than 0.5 , the reference point $x_{e}$ is now closer to the lower payoff $x_{1}$ than the higher payoff $x_{2}$, i.e., $\left|x_{1}-x_{e}\right|=(1-p)\left(x_{2}-\right.$ $\left.x_{1}\right)<\left|x_{2}-x_{e}\right|=p\left(x_{2}-x_{1}\right)$, and thus we are on the steeper part of the utility function in the domain of 
losses rather than in the domain of gains; thus, in this case due to the assumed diminishing marginal utility, as $p$ increases, more utility is gained in the loss domain than is lost in the gain domain, and thus $U^{\prime}(d)<0$. This provides our second theoretical result:

Theoretical Result 2 (Reference-dependence and diminishing marginal utility): As the probability $p$ of observing the bad payoff outcome decreases, increasingly more utility will be received from reporting dishonestly than honestly when $p$ is greater than 0.5 , and less utility will be received from reporting dishonestly than honestly when $p$ is less than 0.5 .

\section{General Case: Reference-dependence and Loss Aversion:}

Both reference dependence and loss aversion predict that as the probability $p$ of observing the bad payoff outcome decreases, increasingly more utility will be received from reporting dishonestly than honestly when $p$ is greater than 0.5 . However, when $p$ is less than 0.5 , loss aversion continues to predict that as $p$ decreases, utility will be increasing when reporting dishonestly than honestly; in contrast, reference dependence predicts that utility of reporting dishonestly than honestly will be decreasing. Given that loss aversion predicts a linearly decreasing effect of $p$ on the utility of reporting dishonestly than dishonestly (equation 7') whereas reference dependence predicts a diminishing positive effect (equation $7^{\prime \prime}$ ), and given $U^{\prime}(d)=0$ at $p=0.5$, continuity implies that there exists a $p^{*}\left(0 \leq p^{*}<0.5\right)$ such that for all $p>p^{*}$ the loss aversion effect is greater than the reference dependence effect.

To explore where the loss aversion effect is greater than the reference-dependent diminishing marginal utility effect, $p^{*}$, we consider the functional form of utility where agents have CRRA preferences, i.e., $g(x)=x^{(1-\mathrm{r})} /(1-r)$ where $r$ is the coefficient of relative risk aversion. We examine CRRA given the extensive experimental economics literature that has estimated this functional form. To address loss aversion, we assume $h(x)=(1+\alpha) g(x)$, with $\alpha>0$. With these preferences, it is easy to show that $p^{*}=1 /\left[\left(e^{\ln (\alpha)} / r\right)+1\right]$. This result indicates that as the degree of loss aversion $\alpha$ increases (i.e., loss aversion is larger), ceteris paribus, $p^{*}$ decreases and the range in which the loss aversion 
effect is greater than the reference dependent effect increases. This result also shows that as the relative degree of risk aversion $r$ increases (i.e., agents have greater diminishing marginal utility), ceteris paribus, $p^{*}$ increases and the range in which the reference dependent effect is greater than the loss aversion effect increases.

Figure 1 provides a graphical example of the difference in utility from reporting dishonestly vs. honestly, $\mathrm{U}(d)$, for an agent with CRRA utility. We assume that losses are twice as steep as gains $(\alpha=2)$ as is commonly estimated (e.g., Kahneman and Tversky 1992; Abdellaoui et al., 2007). We consider $r=0.3, r=0.5$ and $r=0.7$, as these values are within the range commonly estimated in the literature (e.g., Eckel and Grossman, 2008; Holt and Laury, 2002). Figure 1 shows that $p^{*}$ is greater for agents with greater relative risk aversion; for example, $p^{*}=0.09,0.20$ and 0.27 for $r=0.3,0.5$ and 0.7 respectively. Consistent with Results 1 and 2 (and Result 3 below), Figure 1 also shows that as $p$ decreases from 1 to $p^{*}$ the agent receives increasingly more utility from reporting dishonestly than honestly, and that as $p$ further decreases below $p^{*}$ the relative benefits of reporting dishonestly start to decrease. Note that in our experiments, we examine values of $p=0.125, p=0.5$ and $p=$ 0.875; for these values of $p$, indicated with vertical lines, Figure 1 shows that for these common values of loss aversion and risk aversion the utility of reporting dishonestly $v s$. honestly is strictly greater as $p$ decreases: $\mathrm{U}(d \mid p=0.125)>\mathrm{U}(d \mid p=0.5)>\mathrm{U}(d \mid p=0.875)$.

In sum, Theoretical Results 1 and 2 lead to the following summary of the combined theoretical prediction for agents that have reference-dependent loss-averse preferences with diminishing marginal utility:

Theoretical Result 3 (Reference-dependence and loss-aversion with diminishing marginal utility): As the probability $p$ of observing the low payoff outcome decreases, increasingly more utility will be received from reporting dishonestly than honestly when $p$ is greater than $p^{*}$. Moreover, $p^{*}$ will decrease the more loss averse and the less risk averse the agent is. 
Finally, if we assume the CRRA functional form of utility and standard values for relative risk aversion and loss aversion, then the loss aversion effect will dominate the diminishing marginal utility effect for values of $p>p^{*}$ in the range of $0.09 \leq p^{*} \leq 0.25$ (see Figure 1).

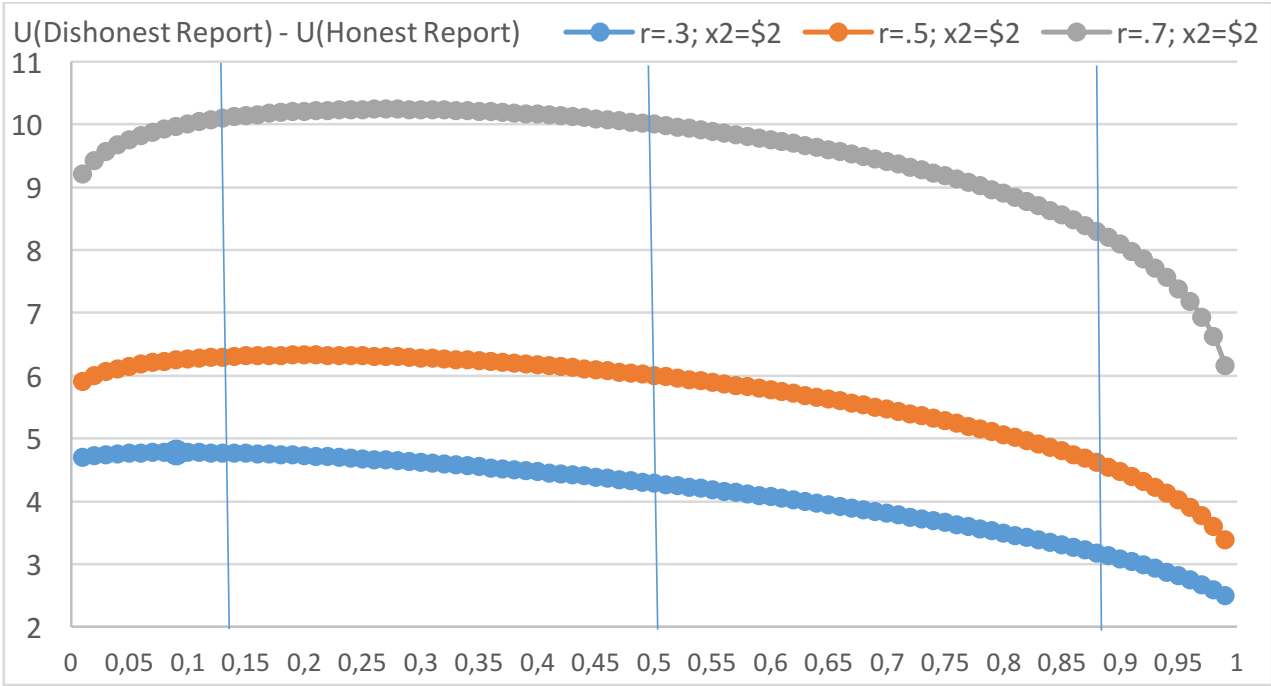

Figure 1: Utility of reporting dishonestly vs. honestly (d) as a function of the probability of the low payoff outcome

Note: Utility functions of losses and gains assume CRRA utility with losses twice as steep as gains, assuming the low payoff is $\$ 0$ and the high payoff is $\$ 2\left(x_{2}=\$ 2\right)$. Vertical lines represent the values of $p(0.125,0.5,0.875)$ used in the experiments reported in section 5.

\section{A precise estimate of the full distribution of dishonesty in experiments}

This section presents our technique to estimate the full distribution of the percent of subjects lying. We first explain our method in the case of two payoffs and then generalize to the case of $m$ payoffs. Two payoffs

Consider N subjects who privately observe the outcome of a random device (e.g., die rolls; coin tosses) and report one of two possible payoffs: $x_{1}$ and $x_{2}\left(x_{1}<x_{2}\right)$ that map directly from the random device (e.g., Tails pays $\$ 0$, Heads pays $\$ 5 ; 1-5$ on the die pays $\$ 0,6$ pays $\$ 2$ ). Outcomes $x_{1}$ and $x_{2}$ occur with probabilities $p$ and 1-p, respectively. If $\mathrm{R}$ subjects $(0 \leq \mathrm{R} \leq \mathrm{N})$ report the higher outcome $x_{2}$, we want to know the probability distribution of the percent of subjects who observed the low outcome $x_{1}$ but reported dishonestly the high outcome $x_{2}$. 
As is common in the literature, we assume that any subject who reports the low outcome $x_{1}$ reports truthfully. ${ }^{12}$ Letting $\mathrm{T}$ be the number of subjects that observed the high outcome ( $\mathrm{T}$ is unobserved by the researcher), there are $\mathrm{R}+1$ different possible numbers of subjects that could have observed the high outcome (i.e., $0 \leq \mathrm{T} \leq \mathrm{R}$ ). For each possible $\mathrm{T}$, the percent of subjects who lied is:

$$
\mathrm{L}_{\mathrm{T}, \mathrm{R}, \mathrm{N}}=[\mathrm{R}-\mathrm{T}] /[\mathrm{N}-\mathrm{T}]
$$

where the numerator is the difference between the number of subjects who reported the high outcome and the number of subjects that observed the high outcome (i.e., the number who were dishonest), and the denominator is the difference between the number of subjects in the experiment and the number that observed the high outcome (i.e., the number who could have been dishonest).

To examine the probability of each possible realization of $\mathrm{T}$, note that $\mathrm{Q}_{\mathrm{T}, \mathrm{N}, p}=[(\mathrm{N} ! /(\mathrm{T} ! *(\mathrm{~N}-$ $\mathrm{T}) !)]^{*} p^{\mathrm{T}} *(1-p)^{(\mathrm{N}-\mathrm{T})}$ is the unconditional probability that $\mathrm{T}$ subjects would observe the high outcome if we allowed all possible observations for $\mathrm{T}$ from $\mathrm{T}=0$ to $\mathrm{N}$. However, since we assume no subject is dishonest to report the low outcome if he observed the high one, there are at least N-R subjects that observed the low outcome, and thus the unobserved number of subjects $\mathrm{T}$ that observed the high outcome cannot exceed R. Thus, the probability that T subjects would have observed the high outcome when R subjects reported the high outcome is:

$$
\mathrm{P}_{\mathrm{T}, \mathrm{N}, \mathrm{R}, p}=\frac{Q_{T, N, p}}{\sum_{k=0}^{R} Q_{k, N, p}} \text { for all } \mathrm{T}=0 \text { to } \mathrm{R}
$$

where the numerator is the probability of the realization of $\mathrm{T}$ based on the binomial distribution with $\mathrm{N}$ observations, R successes and probability $p$. The denominator adjusts up these probabilities by the cumulative likelihood that between 0 and R subjects observed the high outcome. ${ }^{13}$

The PDF that $y=\mathrm{L}_{\mathrm{T}, \mathrm{R}, \mathrm{N}}$ subjects were dishonest when $\mathrm{R}$ subjects reported the high outcome is:

\footnotetext{
${ }^{12}$ It is possible to relax this assumption (e.g., we could allow for decision error so that with probability $\varepsilon_{\mathrm{j}}$ subject $j$ reports an outcome that he did not intend to report). While we expect decision error are extremely unlikely given the simplicity of the task, and would likely be symmetric, we cannot rule out that no errors occur and leave this for future research. ${ }^{13}$ In personal correspondence, David Hugh-Jones notes that our adjustment of the denominator can over-estimate the percent of lying when the sample is small and when the true percent of subjects who lie is also small. A Bayesian approach and Maximum Likelihood estimation may correct this bias, but is beyond the scope of this paper.
} 


$$
\operatorname{Pr}\left(y=\mathrm{L}_{\mathrm{T}, \mathrm{R}, \mathrm{N}}\right)=\mathrm{P}_{\mathrm{T}, \mathrm{N}, \mathrm{R}, p}
$$

The CDF that $\mathrm{L}_{\mathrm{T}, \mathrm{R}, \mathrm{N}}$ or more subjects lied follows directly by summing over the PDF:

$$
\operatorname{Pr}\left(y \geq \mathrm{L}_{\mathrm{T}, \mathrm{R}, \mathrm{N}}\right)=\sum_{k=0}^{T}\left(P_{k, R, N, p}\right)
$$

The expected percent of subjects who lied, $\mathrm{E}_{\mathrm{N}, \mathrm{R}, p}$, is the sum (over all possible observations $\mathrm{T}$ given R subjects reported the high outcome) of the percent of subjects who were dishonest weighted by the probability that $\mathrm{T}$ subjects observed the low outcome:

$$
\mathrm{E}_{\mathrm{N}, \mathrm{R}, p}=\sum_{T=0}^{R}\left(P_{T, R, N, p} * L_{T, R, N}\right)
$$

Finally, the lower bound for the Confidence Interval ( $p$ value) that $y$ subjects were dishonest is simply the minimum value of $\mathrm{L}_{\mathrm{T}, \mathrm{R}, \mathrm{N}}$ such that:

$$
p / 2<\operatorname{Pr}\left(y \geq \mathrm{L}_{\mathrm{T}, \mathrm{R}, \mathrm{N}}\right),
$$

and the upper bound for the Confidence Interval ( $p$ value) that $y$ subjects were dishonest is simply the maximum value of $\mathrm{L}_{\mathrm{T}, \mathrm{R}, \mathrm{N}}$ such that:

$$
\operatorname{Pr}\left(y \geq \mathrm{L}_{\mathrm{T}, \mathrm{R}, \mathrm{N}}\right)<1-p / 2
$$

\section{More than two payoffs}

Researchers may also want to understand dishonesty when there are more than two outcomes. This can be accomplished in an experiment by having more payoffs (e.g., across die outcomes or multiple coin tosses). Consider $m$ distinct outcomes $x_{1}, \ldots, x_{m}$ with probability $p_{1}, \ldots, p_{m}$, respectively, with $x_{1}$ $<x_{2}<\ldots<x_{m}$. The question we address is what percent of subjects who observe an outcome below some threshold $x_{k}(1<k \leq m)$ are dishonest and report an outcome equal to or above $k .^{14}$ To examine the expected percent of subjects who act dishonestly to avoid the worst $k$ - 1 outcomes to obtain one of the best $m-k$ outcomes, let $p=p_{1}+\ldots+p_{k-1}$ and then follow the procedure for two outcomes.

\footnotetext{
${ }^{14}$ Researchers may also be interested in partial lying (e.g., to examine how many subjects lie from one outcome $\mathrm{x}_{\mathrm{k}}$ to $x_{j}(k$ $<j)$ ) to measure small $v s$. big lies. We believe the techniques to estimate partial lies can be developed from the methods presented in this paper, but leave it for future work as it requires technical sophistication beyond the scope of this paper.
} 
Bifurcating the data into two payoff groups might be interesting in a variety of cases. For instance, if payoffs are similar for the lowest $k$ - 1 outcomes and distinctly higher and similar for the top $m-k$ outcomes, or as we are interested in this paper, to study whether subjects want to either avoid the lowest possible outcome $(k=2)$ or obtain the highest possible outcome $(k=m)$.

\section{Implementation}

Using the full distribution of possible outcomes, we can directly calculate the expected percent of subjects who were dishonest conditional on having received the low payoff outcome $(\mathrm{s})\left(\mathrm{E}_{\mathrm{N}, \mathrm{R}, p}\right)$, and the PDF $\left(\mathrm{P}_{\mathrm{T}, \mathrm{N}, \mathrm{R}, p}\right)$ and $\mathrm{CDF}\left(\operatorname{Pr}\left(y \geq \mathrm{L}_{\mathrm{T}, \mathrm{R}, \mathrm{N}}\right)\right.$. Using the CDF, we can also estimate the confidence interval (CI, hereafter) for any level of significance to determine the minimum and maximum percent $y$ who were dishonest. Thus, we are able to examine not only whether subjects were dishonest, but also a) the mean expected percent who were dishonest, b) the minimum and maximum percent we can be confident were dishonest (the lower and upper bounds on the CI), and c) using the CDFs, whether two (or more) treatments significantly differ for any statistic of interest including for instance at the means, medians, quantiles and over the full distribution, using non-parametric tests.

Table 1 provides a few examples with $\mathrm{N}=100$ subjects and $\mathrm{R}=60$ subjects who report the high outcome. When $p=50 \%$, we can reject that all subjects were honest at the $90^{\text {th }}$ and $95^{\text {th }}$ percent CI, but not at the $99^{\text {th }}$ percent. At the $90^{\text {th }}, 95^{\text {th }}$ and $99^{\text {th }}$ percent CI, we can be confident that at least $7.0 \%, 4.5 \%$ and $0.0 \%$ of subjects were dishonest, respectively, and at most $32.0 \%, 33.7 \%$ and $36.9 \%$ were dishonest. If the likelihood of the high outcome was lower, falling from $60 \%$ to $50 \%$, to $40 \%$, to $10 \%$, to $3 \%$, we would be $95 \%$ confident that at least $0.0 \%, 0.0 \%, 21.3 \%, 52.5 \%$ and $57.3 \%$ were dishonest, respectively, and at most $22.3 \%, 36.9 \%, 42.9 \%, 58.3 \%$ and $60 \%$ were dishonest. ${ }^{15,16}$

\footnotetext{
${ }^{15}$ Given $\mathrm{R}=60$ subjects out of the $\mathrm{N}=100$ subjects reported the higher outcome, we assume that the highest possible percent who could have been dishonest is $60 \%$.

${ }^{16}$ Following from footnote 7, Abeler et al.'s (2016) approach would indicate $20 \%$ lying in examples 1-3 of Table 1, and $0 \%, 33.3 \%, 55.6 \%$ and $58.8 \%$ for examples 4 through 7 . Thus, their formula gives a reasonable approximation (within $2 \%$ ) of the true expected percent that lied in six of the seven cases, but is off by $8 \%$ in example 4 .
} 
Table 1. Illustration of the method of estimation of the percent of dishonest subjects

\begin{tabular}{c|cccc|ccc}
\hline \multirow{2}{*}{ Example } & \multicolumn{4}{|c|}{ Inputs } & \multicolumn{3}{c}{ Outputs } \\
\cline { 2 - 7 } & $\mathrm{N}$ & $\mathrm{R}$ & $p$ & $\mathrm{CI}$ & $\mathrm{EV}$ & Lower bound & Upper bound \\
\hline 1 & 100 & 60 & $50 \%$ & $95 \%$ & $19.63 \%$ & $4.45 \%$ & $33.72 \%$ \\
2 & 100 & 60 & $50 \%$ & $90 \%$ & $19.63 \%$ & $6.98 \%$ & $31.95 \%$ \\
3 & 100 & 60 & $50 \%$ & $99 \%$ & $19.63 \%$ & $0.0 \%$ & $36.91 \%$ \\
4 & 100 & 60 & $40 \%$ & $95 \%$ & $7.88 \%$ & $0.0 \%$ & $22.31 \%$ \\
5 & 100 & 60 & $60 \%$ & $95 \%$ & $32.88 \%$ & $21.25 \%$ & $42.85 \%$ \\
6 & 100 & 60 & $90 \%$ & $95 \%$ & $55.51 \%$ & $52.51 \%$ & $58.32 \%$ \\
7 & 100 & 60 & $97 \%$ & $95 \%$ & $60.00 \%$ & $57.31 \%$ & $60.00 \%$ \\
\hline
\end{tabular}

Notes: $\overline{\mathrm{N}}=$ number of subjects; $\mathrm{R}=$ number who report the higher outcome; $p=$ probability of the lower outcome; $\mathrm{CI}=$ confidence interval; $\mathrm{EV}=$ expected value; lower and upper bound of the $\mathrm{CI}$.

\section{Reexamination of the existing literature}

To test the prediction of loss aversion on lying, we first apply our technique to estimate the mean percent of individuals reporting dishonestly across previous studies. Specifically, the objective is to test the hypothesis that there will be a negative correlation between the likelihood of a low payoff outcome and the percent of dishonest reports.

To create our dataset, we started from the 72 studies identified in Abeler et al.'s (2016) metaanalysis. We retained the same inclusion criteria they used. Specifically, we include studies in which subjects have to report the private realization of a random device (a die, a coin, a ticket or a card) that is unobservable to anyone other than the subject, and without any risk of detection during or after the experiment. We also include 'mind games' in which subjects report the number of times they were able to correctly predict (to themselves) the outcome of a random device. We exclude studies in which the subject's payoff depends on strategic interactions with other players, but we retain those in which the report may affect other people. We exclude the treatments in which there is no variation in the monetary incentives associated with all possible realizations of the random device. When the data to calculate the mean lying rates were not available in the paper, we contacted the authors and included all of the studies in which the authors provided us with this additional information. 
In total, our analysis includes 74 studies and 363 treatments, involving 33540 individuals from 44 countries and representing 252831 decisions (see Appendix Table A1). ${ }^{17}$ Sixty-nine percent of these studies have been conducted by a team involving at least one economist; $53 \%$ of the treatments have been run in a standard laboratory setting with standard student-subjects pools; $14 \%$ are from artefactual field experiments conducted as in a lab setting but involving atypical subjects; $28 \%$ of the treatments involved no direct contact with an experimenter for reporting (mostly conducted on-line); $5 \%$ involved verbal reporting (through the telephone or direct interaction with an experimenter).

When there are only two possible outcomes (for example in a single coin tossing task or when there are only two payoffs for all possible die rolls) we calculate the percent of subjects who lie to get the high payoff when they observed a low outcome. This calculation requires only knowing the total number of subjects, the number of subjects reporting the high outcome, and the probability of getting the low outcome. When there are more than two possible outcomes, we estimate two statistics: first, the percent of people who lied to avoid the lowest payoff and second, the percent who lied to get the highest payoff, i.e. framing all payoffs, except the highest one, as bad outcomes. In the case of repeated decisions (up to 20 coin tosses or card draws and up to 75 die rolls), we define the lowest and the highest outcomes as those associated with the bottom $5 \%$ and the top $5 \%$ outcomes of the theoretical distribution, respectively. ${ }^{18}$

Figure 2 displays our estimated mean percent of subjects lying to avoid the lowest payoff in the reviewed studies as a function of the likelihood of the lowest outcome. In panel A, the $x$-axis represents the probability of the lowest outcome and the $y$-axis represents the mean percent lying.

\footnotetext{
${ }^{17}$ The percentage of data overlapping with the meta-analysis of Abeler et al. (2016) is 93\%. We include 69 of their 72 studies and add 5 new ones. Three of their studies were not included because the data available did not allow us to measure the lying rates.

${ }^{18}$ For example, when subjects have to predict the outcome of 20 coin tosses and earn money that monotonically increases with the number of correct predictions, the bad (good) outcome is defined as getting at most 6 (at least 14, resp.) correct guesses (with $p=0.057$ ). The $5 \%$ threshold is arbitrary, but it allows us to avoid studying extremely rare events such as 2 ${ }^{20}$ in the case of predicting all 20 coin tosses incorrectly or $1-2^{-20}$ in the case of predicting all 20 coin tosses correctly.
} 
Each treatment in every study gives one observation. Panel B aggregates this information for various probability intervals. In Figure 3, we consider instead the relationship between the estimated mean percent of subjects lying to avoid the low payoff, when the latter is defined as any payoff except the highest one, and the likelihood of not getting the highest outcome.

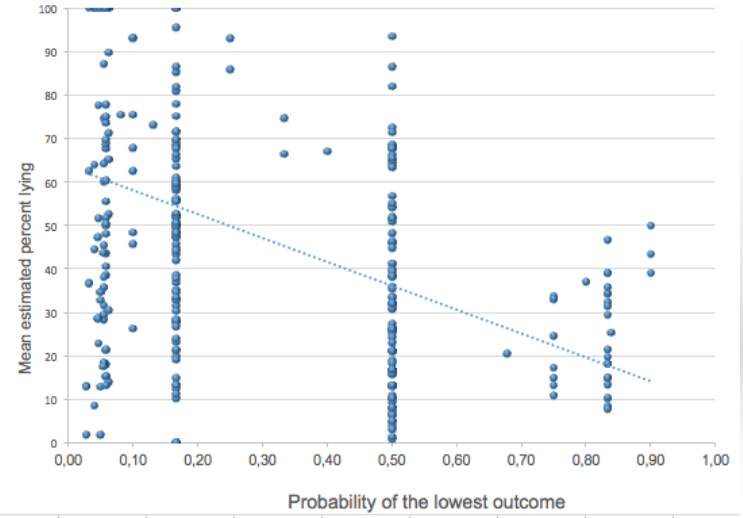

A

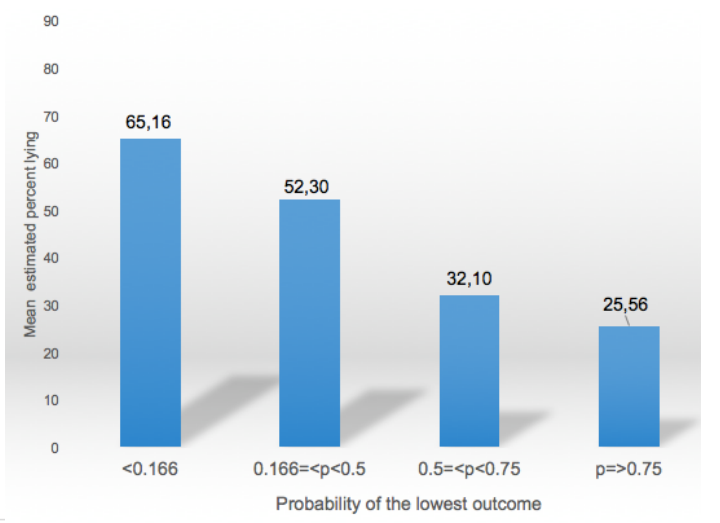

$\mathrm{B}$

Figure 2: Mean estimated percent of subjects lying to avoid the lowest payoff by the likelihood of the lowest outcome, literature review

Note: In Panel B, the bar with $p<0.166$ corresponds to 120 treatments and 12237 subjects, the bar with $0.166 \leq p<0.5$ corresponds to 95 treatments and 11050 subjects, the bar with $0.5 \leq p<0.75$ corresponds to 107 treatments and 7214 subjects, the bar with $p \geq 0.75$ corresponds to 37 treatments and 3787 subjects. In total, we have 359 treatments instead of 363 in this figure because in one study information was not available at the treatment level.

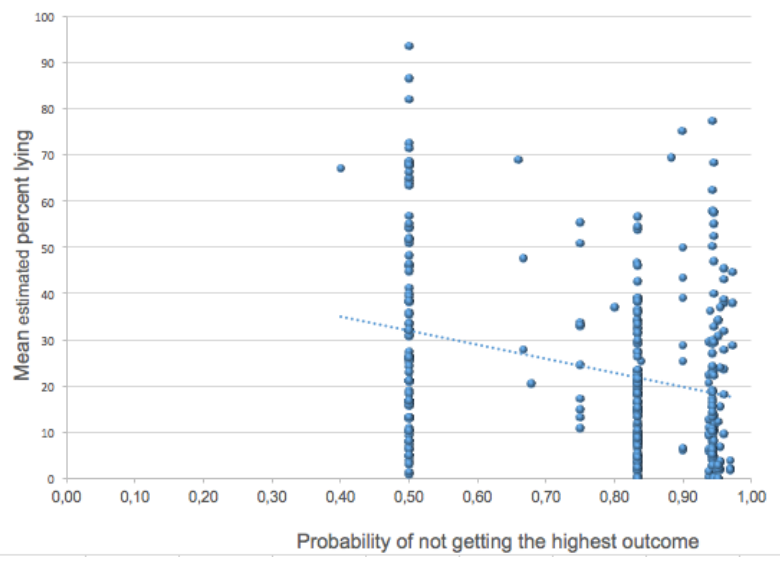

A

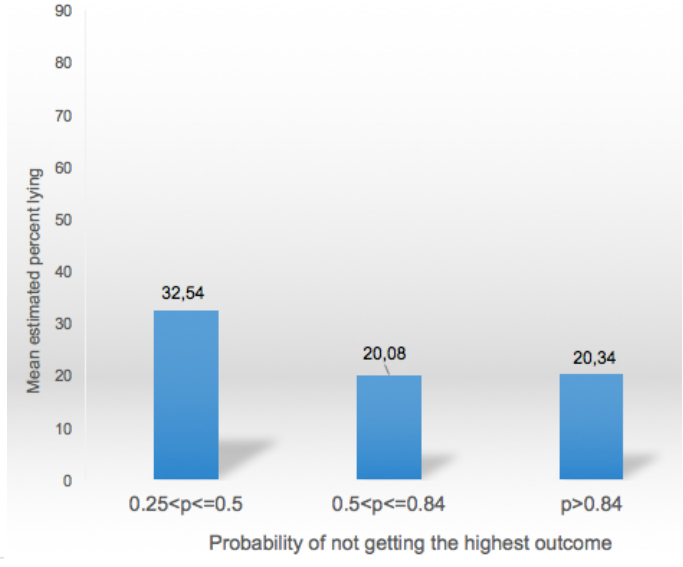

$\mathrm{B}$

Figure 3: Mean estimated percent of subjects lying to avoid a low payoff by the likelihood of not getting the highest outcome, literature review

Note: In Panel B, the bar with $0.25<p \leq 0.5$ corresponds to 107 treatments and 7395 subjects, the bar with $0.5<p \leq 0.84$ to 134 treatments and 14922 subjects, the bar with $p>0.84$ to 122 treatments and 12591 subjects.

Consistent with loss aversion, these figures show a clear negative relationship between the estimated mean lying rate and the likelihood of the bad outcome, regardless of whether it is defined 
as the lowest outcome or any outcome except the highest. Due to the large variance in lying across studies for a given probability, we have further analyzed the data using linear regressions in which the dependent variable is the mean estimated lying rate with each treatment serving as one observation. Robust standard errors are clustered at the study level and sample weighting allows us to control for the large diversity of sample sizes across studies. Table 2 reports the results. In models (1) to (3), the bad outcome is defined as the lowest payoff outcome, whereas in models (4) to (6) it is defined as any outcome except the highest. In models (1) and (4), the only independent variable is our main variable of interest: the probability of the bad outcome. Models (2) and (5) augment the previous models by including the expected values of the lowest/bad outcome and of the good/highest outcome, converted from local currencies to US Dollars by 2015 Purchasing Power Parities. ${ }^{19}$ They also include a number of controls relative to the experimental environment because they can potentially influence lying: "Direct Report," "Laboratory" and "Online” are dummy variables equal to 1 if the experiment was conducted with an experimenter getting reports directly from subjects (in person or on the telephone), the experiment was conducted in a standard university lab setting, and if the subjects did not interact with the experimenters when reporting (typically, online experiments), respectively, and equal 0 otherwise. The reference category is thus artefactual field experiments conducted like in a lab environment but with non-student subjects. "Die task" is equal to 1 if the task involved dice, and to 0 if other random devices were used. "Mind game" is a dummy variable indicating whether subjects had to guess in their head the outcome of the random device and report the number of correct predictions. "Number of decisions" captures the number of reports made by the same subject in a treatment. Finally, "Economics affiliation" indicates whether the study has been

\footnotetext{
${ }^{19}$ For example, suppose a die task in which each dot pays $\$ 1$, except when the subject rolls a 6 . Conditional on getting the lowest outcome, the expected value of this lowest outcome is $\$ 0$, while the expected value of a good outcome is $\$ 3$. Conditional on getting the highest outcome, the expected value of the highest outcome is $\$ 5$, while the expected value of a bad outcome is $\$ 2$.
} 
conducted by a team involving economists, as opposed to studies conducted by other social scientists. In models (3) and (6) we add country dummies.

Table 2. Likelihood of the bad outcome as a determinant of the mean lying rate

\begin{tabular}{|c|c|c|c|c|c|c|}
\hline \multirow{2}{*}{$\begin{array}{l}\text { Dep. Variable: } \\
\text { Mean lying rate }\end{array}$} & \multicolumn{3}{|c|}{ Lying to avoid the lowest outcome } & \multicolumn{3}{|c|}{ Lying to avoid a bad outcome } \\
\hline & (1) & (2) & (3) & (4) & $(5)$ & (6) \\
\hline $\begin{array}{l}\text { Probability of the } \\
\text { lowest outcome }\end{array}$ & $\begin{array}{c}-0.423 * * * \\
(0.095)\end{array}$ & $\begin{array}{c}-0.377 * * * \\
(0.069)\end{array}$ & $\begin{array}{c}-0.365 * * * \\
(0.079)\end{array}$ & - & - & - \\
\hline $\begin{array}{l}\text { Probability of a bad } \\
\text { outcome }\end{array}$ & - & - & - & $\begin{array}{c}-0.539 * * * \\
(0.200)\end{array}$ & $\begin{array}{c}-0.808 * * * \\
(0.173)\end{array}$ & $\begin{array}{c}-0.627 * * * \\
(0.145)\end{array}$ \\
\hline $\begin{array}{l}\text { EV of the lowest } \\
\text { outcome }\end{array}$ & - & $\begin{array}{l}-0.003 \\
(0.003)\end{array}$ & $\begin{array}{l}-0.003 \\
(0.003)\end{array}$ & - & - & - \\
\hline $\begin{array}{l}\text { EV of a good } \\
\text { outcome }\end{array}$ & - & $\begin{array}{l}0.0003 \\
(0.001)\end{array}$ & $\begin{array}{l}0.0005 \\
(0.001)\end{array}$ & - & - & - \\
\hline $\begin{array}{l}\text { EV of a bad } \\
\text { outcome }\end{array}$ & - & - & - & - & $\begin{array}{c}-0.003 * * * \\
(0.001)\end{array}$ & $\begin{array}{c}-0.003 * * * \\
(0.001)\end{array}$ \\
\hline $\begin{array}{l}\text { EV of the highest } \\
\text { outcome }\end{array}$ & - & - & - & - & $\begin{array}{c}0.002 * * * \\
(0.0005)\end{array}$ & $\begin{array}{c}0.002 * * * \\
(0.0004)\end{array}$ \\
\hline Direct report & - & $\begin{array}{c}-0.256^{* * *} \\
(0.065)\end{array}$ & $\begin{array}{c}-0.164 * * \\
(0.070)\end{array}$ & - & $\begin{array}{c}-0.268 * * * \\
(0.070)\end{array}$ & $\begin{array}{c}-0.222 * * * \\
(0.077)\end{array}$ \\
\hline Laboratory & - & $\begin{array}{c}0.206 * * * \\
(0.068)\end{array}$ & $\begin{array}{c}0.244 * * * \\
(0.048)\end{array}$ & - & $\begin{array}{c}0.178 * * * \\
(0.033)\end{array}$ & $\begin{array}{c}0.130 * * * \\
(0.028)\end{array}$ \\
\hline Online & - & $\begin{array}{c}0.048 \\
(0.069)\end{array}$ & $\begin{array}{l}0.132 * * \\
(0.051)\end{array}$ & - & $\begin{array}{c}0.061 \\
(0.065)\end{array}$ & $\begin{array}{l}0.091 * * \\
(0.042)\end{array}$ \\
\hline Mind game & - & $\begin{array}{l}-0.064 \\
(0.059)\end{array}$ & $\begin{array}{c}0.045 \\
(0.059)\end{array}$ & - & $\begin{array}{c}0.006 \\
(0.046)\end{array}$ & $\begin{array}{c}0.031 \\
(0.042)\end{array}$ \\
\hline Die task & - & $\begin{array}{c}-0.143 * * \\
(0.059)\end{array}$ & $\begin{array}{l}-0.098 * \\
(0.057)\end{array}$ & - & $\begin{array}{l}-0.035 \\
(0.058)\end{array}$ & $\begin{array}{c}0.028 \\
(0.049)\end{array}$ \\
\hline Number of decisions & - & $\begin{array}{c}0.008 * * * \\
(0.002)\end{array}$ & $\begin{array}{c}0.005 * * * \\
(0.002)\end{array}$ & - & $\begin{array}{c}0.008 * * * \\
(0.002)\end{array}$ & $\begin{array}{c}0.006 * * * \\
(0.001)\end{array}$ \\
\hline Economics affiliation & - & $\begin{array}{l}0.064 \\
(0.50)\end{array}$ & $\begin{array}{c}0.032 \\
(0.051)\end{array}$ & - & $\begin{array}{c}0.058 \\
(0.047)\end{array}$ & $\begin{array}{c}0.036 \\
(0.029)\end{array}$ \\
\hline Country dummies & No & No & Yes & No & No & Yes \\
\hline Constant & $\begin{array}{c}0.627 * * * \\
(0.038)\end{array}$ & $\begin{array}{c}0.499 * * * \\
(0.074)\end{array}$ & $\begin{array}{c}0.494 * * * \\
(0.068)\end{array}$ & $\begin{array}{c}0.683 * * * \\
(0.173)\end{array}$ & $\begin{array}{c}0.715^{* * *} \\
(0.162)\end{array}$ & $\begin{array}{c}0.590 * * * \\
(0.138)\end{array}$ \\
\hline $\mathrm{Nb}$ observations & 359 & 359 & 359 & 363 & 363 & 363 \\
\hline $\mathrm{Nb}$ clusters & 74 & 74 & 74 & 74 & 74 & 74 \\
\hline $\mathrm{R}^{2}$ & 0.15 & 0.351 & 0.524 & 0.177 & 0.496 & 0.664 \\
\hline
\end{tabular}

Note: Table 2 reports OLS estimates with robust standard errors (in parentheses) clustered at the study level and sample weighted. Each treatment gives one observation. 4 observations are missing in models (1) to (3) because information on lying to avoid the lowest outcome was not available at the treatment level in one study. ***, **, and * indicate significance at the $0.01,0.05$ and 0.10 level, respectively.

Consistent with Figures 2 and 3, all specifications reported in Table 2 show that the mean lying rate increases significantly $(p<0.01)$ when the likelihood of the bad outcome decreases. This effect is robust to either measure of lying (to avoid the lowest payoff or to get the highest payoff). Moreover, the magnitude of the estimated effect is substantial; for instance, if we compare a die roll with a $5 / 6$ 
chance to observe the bad outcome to a coin toss with a $50 \%$ chance to observe the bad outcome, ceteris paribus, the estimate with all the controls (Model 6) predicts 20.9 percentage points $([(5 / 6)$ $\left.(1 / 2)]^{*} 0.627\right)$ more subjects will lie in the coin toss condition. ${ }^{20}$

The regressions also show that the expected values have an impact consistent with expected utility maximizers with diminishing marginal utility over money; in particular, as the expected value of the bad payoff increases (so the marginal utility of an extra dollar if lying is smaller), less subjects lied; and as the expected payoff of the highest outcome increases (so there is a greater increase in payoffs to lie), more subjects lied. These results are directional in the analysis of lying to avoid the lowest payoff, and significant in the analysis of lying to get the highest payoff. $^{21}$

Overall, the findings from our analysis of the extant literature supports our prediction (Theoretical Result 1) about the role of loss aversion in lying. However, alternative explanations might also be at play. One potential additional explanation for the effect of the probability of the bad outcome on lying could be reputation concerns (Gneezy et al., 2016; Dufwenberg and Dufwenberg, 2016). For instance, consistent with reputation concerns, Table 2 shows that subjects lie less when they have to report verbally to the experimenter (the "Direct Report" estimate is negative and significant). Thus, we now present evidence from two experiments run to $a$ ) isolate and further test the loss aversion lying hypothesis, $b$ ) eliminate across experiment differences in the extant literature (e.g., different recruitment, subjects, tasks and payoffs), and $c$ ) exclude reputation concern effects.

\footnotetext{
${ }^{20}$ We re-estimated the six models in Table 2 adding the square of the probability of the lowest (or bad) outcome to test for evidence of the reference dependence diminishing marginal utility implication that an increase in the probability could have a positive effect for low values of $p$ (see Figure 1). However, in these regressions (available upon request) the squared term is never significant. This suggests that either $p^{*}$ is close to zero, we do not have enough observations with low enough values of $p$, the loss aversion effect dominates the reference dependence effect for the lowest values of $p$ we observe, we do not have enough power to detect this effect, or the implication is incorrect. Experiments could easily be designed to test the reference dependence implication, but in this study we focus on the loss aversion hypothesis.

${ }^{21}$ In alternative specifications (available upon request), we replaced the expected values by the maximum and the minimum payoffs. These variables were never significant. We also replaced the expected maximum payoff with the difference in the expected payoffs from reporting the maximum and minimum payoffs. Again, these variables were never significant. Since the $\mathrm{R}^{2}$ is not higher in these alternative specifications, we omit reporting them.
} 


\section{Two within-study tests of loss aversion and lying}

In this section, we test whether the relationship between the probability of observing the bad outcome and the percent of subjects lying holds when we directly manipulate the probability of the outcomes, remove the variations in conditions that exist between studies in the literature, and eliminate potential reputation concern effects. In our first experiment, we vary the probability distribution of outcomes, ceteris paribus, to earn a fixed payoff for oneself. In our second experiment, we test the robustness of this relationship in a setting where the beneficiary of the lie is not the subject, but a cause that the subject either supports or opposes.

\subsection{Study 1: Lying for self}

\section{Experimental design and procedures ${ }^{22}$}

This experiment is based on a mind coin tossing game. ${ }^{23}$ Subjects have the opportunity to earn money for themselves depending on their ability to predict the outcome of three coin tosses. They are instructed to toss a coin three times, but before each toss they have to predict which side of the coin will be face-up. They have to report only the number of correct guesses. Thus, they can inflate their actual success by misreporting the number of correct guesses. The major advantage of the mind game process is that the subjects know that their outcome cannot be scrutinized: the experimenter cannot observe the prediction or the actual outcome of the coin toss. To eliminate reputation concerns, the experiment was run online and double-anonymous; it was common knowledge that the experimenter never knew the identity of the subjects. Therefore, individuals should have no reason to disguise a lie to maintain a positive image with other subjects or the experimenters. ${ }^{24}$

\footnotetext{
22 The full instructions for both experiments are available in the online Appendix. Web link accessible as of 06/12/2016 https://az1.qualtrics.com/ControlPanel/?ClientAction=EditSurvey\&Section=SV bI9ZO3D013uo61v\&SubSection=\&Sub SubSection $=\&$ PageActionOptions $=\&$ TransactionID $=1 \&$ Repeatable $=0$

${ }^{23}$ Mind games have been used mainly with a die (Jiang, 2013; Shalvi and de Dreu, 2014; Barfort et al., 2015; Kajackaite and Gneezy, 2015; Potters and Stoop, 2015), rarely with coin tosses (Shalvi, 2012).

${ }^{24}$ Kajackaite and Gneezy (2015) find that some people may not lie in non-mind games such as Fischbacher and FöllmiHeusi (2013) because they want to disguise a lie due to concerns with scrutiny.
} 
The study involves three between-subject treatments that vary the probability of observing the lowest and the highest payoff. In the "0002" treatment, subjects earn $\$ 0$ if they report 0,1 , or 2 correct guesses and they earn $\$ 2$ if they report 3 correct guesses. The probability of observing the low payoff is $87.50 \%$ and the probability of observing the high payoff is $12.50 \%$. In the " 0022 " treatment, subjects earn $\$ 0$ if they report 0 or 1 correct guess and they earn $\$ 2$ if they report 2 or 3 correct guesses. Here, the probability of observing the low payoff or the high payoff is $50 \%$. Finally, in the " 0222 " treatment, subjects earn $\$ 0$ if they report 0 correct guesses and they earn $\$ 2$ if they report at least one correct guess. Here, the probability of observing the low payoff is $12.50 \%$ and the probability of observing the high payoff is $87.50 \%$. Procedures and payoffs are common knowledge.

The experiment was run using Amazon MTurk with 978 U.S. participants. ${ }^{25}$ We varied the number of participants across treatments based on a preliminary statistical power analysis, with the objective of getting approximately the same number of likely opportunities to get the $\$ 0$ payoff in each treatment, and hence the same number of respondents with a financial motive to lie. 80 persons participated in the 0002 treatment, 327 in the 0022 treatment and 571 in the 0222 treatment. After the task was explained carefully (see the online instructions for full details), they tossed a coin and reported the number of correct predictions. We also collected a number of socio-demographic characteristics (including age, gender, highest educational attainment, category of household annual pretax income, mean weekly expenditures). ${ }^{26}$ A summary of our subjects' characteristics by treatment and the effects of these characteristics on payoffs can be found in Appendix Tables A2 and

\footnotetext{
${ }^{25}$ The use of MTurk ensures a double anonymous procedure reinforcing the lack of observation by others. It also enables the collections of a large number of short duration observations from a broad demographic pool. Given the simplicity of the task, we feel confident that participants understood the instructions. Moreover, studies have shown that the quality of data and behavior on MTurk do not differ from that of other sources (e.g., Paolacci et al., 2010; Horton et al., 2011; Suri and Watts, 2011).

${ }^{26}$ We also collected beliefs about the social appropriateness of reporting different outcome combinations using a procedure inspired from Krupka and Weber (2013), and we elicited the person's belief in good luck using a twelve-item questionnaire from psychology (Darke and Freedman, 1997). Since neither of these potential moderators had substantial or consistent effect, they have been removed from the remaining analyses. Details on their content can be seen in the online Appendix Table A2.
} 
A3. ${ }^{27}$ On average, the experiment lasted 7.75 minutes (S.D. $\left.=8.40\right)$ and subjects earned $\$ 3.27$ (S.D. $=$ 0.64) which included a $\$ 1.50$ participation fee.

\section{Results}

Our model predicts that subjects will be more likely to lie to avoid earning $\$ 0$ in the 0222 treatment than in the 0022 , and more likely to lie in the 0022 treatment than in the 0002 treatment. The data confirm these two predictions, as summarized in our first result:

Result 1. Consistent with the loss aversion model presented above, individuals lie more on average to increase their own payoff when observing the low payoff is more unlikely.

Support for Result 1. Table 3 displays summary statistics by treatment, including the distributions of reported outcomes, the $p$-values of $\chi^{2}$ goodness-of-fit tests comparing the empirical distributions of reports with the theoretical distribution, the $p$-values of binomial tests comparing each category of reported outcome with its theoretical relative frequency, the mean estimated lying rates using our technique, and the associated $95 \%$ confidence intervals.

Table 3 shows that the percentage of reports paying $\$ 0$ is $2.98 \%$ in the 0222 treatment, $16.82 \%$ in the 0022 treatment and $48.75 \%$ in the 0002 treatment, while the theoretical percentages should be $12.50 \%, 50 \%$ and $87.50 \%$, respectively. Binomial tests and $\chi^{2}$ goodness-of-fit tests show that the reports deviate significantly from the theoretical distribution. Our estimation based on the full distribution of reports (assuming that nobody lies downwards) shows that on average $44.18 \%$ of participants who had a financial motive to lie lied in the 0002 treatment, $66.26 \%$ in the 0022 treatment, and $75.88 \%$ in the 0222 treatment. Pairwise comparisons indicate that the differences

\footnotetext{
${ }^{27}$ The various demographics are randomly dispersed across conditions. In study 1, pairwise tests show no significant differences between conditions on gender ( $p>0.14)$, age $(p>0.14)$, education $(p>0.90)$, income $(p>0.07)$, or weekly spending $(p>0.80)$. We cannot estimate lying at the individual level, so to test the effects of covariates we used the participant's payout as a proxy for lying, since those who lied receive the larger payout. The demographic and attitudinal variables have little effect on the participant's payout. Only age consistently reaches the 0.05 level of significance, such that younger people get higher payouts. Additional analyses find no significant interactions of the covariates with the conditions (all $p$-values $>0.05$ ), demonstrating that none of the covariates moderate the effects of treatment on payout.
} 
between the three treatments are significant at the $p<0.01$ level, as there is no overlap between the $95 \%$ confidence intervals. Figure 4 illustrates these findings. ${ }^{28}$

Table 3. Summary statistics, Study 1

\begin{tabular}{lccc}
\hline Treatments & 0222 & 0022 & 0002 \\
\hline Number of reported correct guesses & & & \\
0 & $17(2.98 \%)$ & $13(3.98 \%)$ & $3(3.75 \%)$ \\
1 & $165(28.90 \%)$ & $42(12.84 \%)$ & $11(13.75 \%)$ \\
2 & $308(53.94 \%)$ & $221(67.58 \%)$ & $25(31.25 \%)$ \\
3 & $81(14.19 \%)$ & $51(15.60 \%)$ & $41(51.25 \%)$ \\
$\mathrm{N}$ & $571(100 \%)$ & $327(100 \%)$ & $80(100 \%)$ \\
\hline$p$-values from $\chi^{2}$ goodness-of-fit tests & $<0.001$ & $<0.001$ & $<0.001$ \\
\hline -values from two-sided Binomial tests & & \\
0 correct guess & $<0.001$ & $<0.001$ & 0.016 \\
1 correct guess & $<0.001$ & $<0.001$ & $<0.001$ \\
2 correct guesses & $<0.001$ & $<0.001$ & 0.299 \\
3 correct guesses & 0.229 & 0.094 & $<0.001$ \\
\hline Percent who earned \$0 & $2.98 \%$ & $16.82 \%$ & $48.75 \%$ \\
Expected percent if no lying & $12.50 \%$ & $50.00 \%$ & $87.50 \%$ \\
\hline Mean percent of subjects lying & 75.88 & 66.26 & 44.18 \\
Confidence Interval, 95\% & $70.03-80.62$ & $62.40-69.73$ & $39.39-48.63$ \\
\hline
\end{tabular}

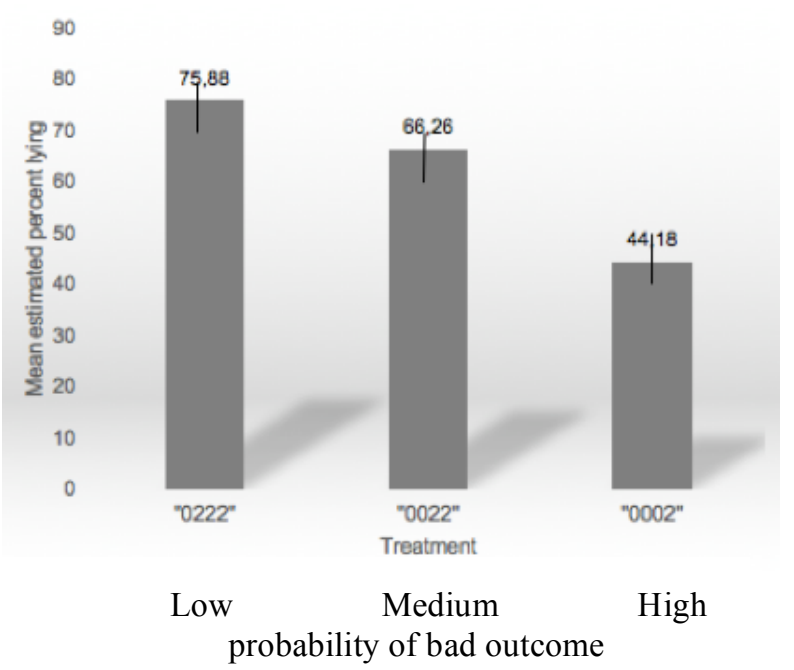

Figure 4. Mean estimated percent of subjects lying, by treatment, Study 1

\footnotetext{
${ }^{28}$ Our findings are consistent with those of Abeler et al. (2016) who also report the results of an experiment in which they shift the distribution of true states. Subjects have to draw one chip out of 50 chips that pay either 4 or 10 GBP. In one treatment, there are 5 chips paying GBP 10 and in the second treatment there are 30 chips paying GBP 10 . They find that people cheat significantly more in the second condition.
} 


\subsection{Study 2: Lying to support or avoid supporting an organization ${ }^{29}$}

To test the robustness from our first experiment, we ran a second experiment using a $2 \times 2$ betweensubject and within-subject design. The within-subject manipulation varies the likelihood of observing the worst and best outcomes and includes an intermediary outcome in the payoff distribution. The presence of three outcomes lets us test whether subjects are more willing to lie to avoid the worst outcome (in order to get the intermediary or best outcome) or to get the best outcome (in order to avoid the worst or intermediary outcome). The second dimension varies the beneficiary of the reported outcome between subjects. The beneficiary is no longer the individual but a cause that the individual either supports or opposes. ${ }^{30}$ This experiment thus gives us two distinct robustness tests: whether subjects lie more as the probability of the bad outcome decreases when (1) lying will benefit a cause they support (by lying either to avoid reporting the bad outcome, or by lying to report the best outcome) and (2) lying will avoid benefiting a cause they oppose (by lying either to avoid reporting the best outcome, or by lying to report the worst outcome). ${ }^{31}$

\section{Experimental design and procedures}

The second experiment is also based on a mind game. In this study, subjects complete two sets of three coin tosses, each set with a different incentive structure. In the " 0018 " treatment, reporting zero or one correct guess pays nothing, while reporting two correct guesses pays $\$ 1$ and reporting three

\footnotetext{
${ }^{29}$ Stimuli available at this address. Web link accessible as of 06/12/2016 https://az1.qualtrics.com/ControlPanel/?ClientAction=EditSurvey\&Section=SV ac4TD3rGA3HZALr\&SubSection=\&Su $\mathrm{bSubSection}=\&$ PageActionOptions $=\&$ TransactionID $=1 \&$ Repeatable $=0$

${ }^{30}$ This constitutes another originality of our study. In the previous literature, when the report of the subject impacts another entity, this entity is usually another subject in the experiment and the deciding player's payoff is also affected (e.g., Conrads et al., 2013; Shalvi and de Dreu, 2014; Meub et al., 2015; Muehlheusser et al., 2015; Weisel and Shalvi, 2015; Amir et al., 2016; Banerjee et al., 2016; Cadsby et al., 2016). We are aware of only one other study where the beneficiary of a lie is a nonprofit organization (Lewis et al., 2012).

31 This design also gives information on whether people are willing to lie when their payoff is not affected. On the one hand, the moral cost of lying is not compensated with a personal monetary benefit, which should discourage lying. Conversely, the moral justification of donating or avoiding donating to a cause you either support or oppose may encourage lying. Moreover, the design lets us test whether subjects are more willing to lie to help a cause they support $v s$. to avoid helping a cause they oppose. We have no a priori hypothesis nor know of any literature that suggests whether lying to support or lying to not help support will be stronger.
} 
correct guesses pays $\$ 8$. In this treatment, the probability of observing the lowest payoff outcome is $50 \%$ and the probability of observing the highest payoff outcome is $12.5 \%$. In the " 0188 " treatment, reporting zero correct guesses pays nothing, reporting one correct guess pays $\$ 1$, and reporting two or three correct guesses pays $\$ 8$. In this treatment, the probability of observing the lowest payoff outcome is $12.50 \%$ and the probability of observingthe highest payoff outcome is $50 \%$. We balanced the order between the two incentive structures across individuals.

Depending on the condition, the beneficiary of the reported outcome is either the Republican National Party (RNP) or the Democratic National Party (DNP) in the U.S. All participants earn a fixed payoff ( $\$ 1.50)$ for themselves that is independent of their reported outcome. At the beginning of the session, we asked subjects to indicate their agreement with the goals of, and desire to help, both the RNP and DNP. We included these questions not only to measure their partisanship, but also to induce them to think about their support or opposition before deciding whether to report honestly or not. Subjects were then matched randomly with one party and were informed that their reported outcome could generate a donation to this party.

This experiment included 422 (different) MTurkers residing in the US. After the decision task, we elicited each subject's political affiliation to identify whether the party he was assigned is one he supports or opposes. In particular, we assume that if a subject states an affiliation with the Democratic (Republican) party, then he would support the cause of the DNP (RNP) and oppose the cause of the RNP (DNP). ${ }^{32}$ If a participant states no affiliation with either the Democratic or Republican party (they indicated any other party or no affiliation with any party), we assume they

\footnotetext{
${ }^{32}$ We use the stated political party affiliation in the analysis because it is the identity reported by the subject, but note that this variable is consistent with our other measures. Those subjects who stated an affiliation with the Democratic party report a mean agreement with the DNP goals of 31.76 (S.D. $=16.73$; range $-50-+50)$ but an agreement of -32.92 (S.D. $=19.10$; range $-50-+50$ ) with the goals of the Republican party. Conversely, those affiliated with the Republican party, agree with the RNP goals (mean 26.71; S.D. $=18.16$; range $-50-+50$ ) and disagree with the DNP goals (mean 27.39; S.D. $=21.79$ ). In contrast, independents show limited agreement with either party's goals (DNP: mean -0.37; S.D. $=25.90$ and RNP: mean -13.41 ; S.D. $=24.87$ ).
} 
neither support nor oppose either party. After reporting the number of correct predictions in the two decisions, subjects also had to decide whether the experimenter would add $\$ 2$, subtract $\$ 2$ or not change the total donation made for each party. At the end of the experiment, one of the four monetized decisions (the two mind games " 0018 " and " 0188 " and the two decisions to either add, subtract or leave unchanged) was chosen at random to be carried out. Overall, 181 (42.89\%) subjects reported an affiliation with the Democratic Party and 80 (18.96\%) with the Republican Party, and $151(35.78 \%)$ self-reported as Independent. Given the importance of (mis-)matching the political affiliations, we retain for the analysis only those who stated a Democrat or Republican affiliation. This left 115 subjects assigned to potentially help their own party and 146 assigned to potentially help the party they oppose.

We elicited the same beliefs and socio-demographic variables as in the first study (see Tables A2 and A4 in Appendix). ${ }^{33}$ After all subjects completed the experiment, the final payoffs to each party were determined and a single payment was made. On average, the experiment lasted 13.02 minutes (S.D. $=11.31)$. Subjects earned a flat fee of $\$ 1.50$ and generated an average of $\$ 2.84$ for the party they were partnered with.

\section{Results}

Table 4 displays summary statistics about the results of Study 2, for each treatment and for three categories of subjects (those who were matched with the party they support, those matched with the party they oppose, and those who reported no affiliation to either the DNP or RNP). It also includes

\footnotetext{
${ }^{33}$ We additionally collected a scale measure of guilt proneness (Cohen et al., 2011) and religiosity (Huber and Huber, $2012)$ as possible covariates. There are no significant differences between conditions on gender $(p>0.69)$, age $(p>0.05)$, education ( $p>0.90)$, income ( $p>0.46)$, weekly spending $(p>0.34)$, political affiliation $(p>0.38)$. As expected, there is a significant difference between agreement with the political goals of the party the participant is donating to, based on whether the person was in the support or oppose condition $(p s<0.001)$. The demographic and attitudinal variables have little effect on the participant's payout. We again see some effect of age, although less consistently strong here, and in the opposite direction as in study 1 , with older respondents reporting higher payouts. Additional analyses find no significant interactions of the covariates with the supporting and opposing conditions (all $p$-values $>0.05$ ), demonstrating that the covariates do not moderate the effects of treatment on payout.
} 
the distributions of reported outcomes, the $p$-values of $\chi^{2}$ goodness-of-fit tests and binomial tests, the mean estimated lying rates, and the associated $95 \%$ confidence intervals.

Table 4. Summary statistics, Study 2

\begin{tabular}{|c|c|c|c|c|c|c|}
\hline & \multicolumn{3}{|c|}{0018 Treatment } & \multicolumn{3}{|c|}{0188 Treatment } \\
\hline & Support & Oppose & Other & Support & Oppose & Other \\
\hline \multicolumn{7}{|c|}{ Number of reported correct guesses } \\
\hline 0 & $\begin{array}{c}5 \\
(4.35 \%)\end{array}$ & $\begin{array}{c}21 \\
(14.39 \%)\end{array}$ & $\begin{array}{c}18 \\
(11.18 \%)\end{array}$ & $\begin{array}{c}3 \\
(2.61 \%)\end{array}$ & $\begin{array}{c}23 \\
(15.76 \%)\end{array}$ & $\begin{array}{c}20 \\
(12.42 \%)\end{array}$ \\
\hline 1 & $\begin{array}{c}40 \\
(34.78 \%)\end{array}$ & $\begin{array}{c}59 \\
(40.41 \%)\end{array}$ & $\begin{array}{c}66 \\
(40.99 \%)\end{array}$ & $\begin{array}{c}30 \\
(26.09 \%)\end{array}$ & $\begin{array}{c}75 \\
(51.37 \%)\end{array}$ & $\begin{array}{c}60 \\
(37.27 \%)\end{array}$ \\
\hline 2 & $\begin{array}{c}48 \\
(41.74 \%)\end{array}$ & $\begin{array}{c}59 \\
(40.41 \%)\end{array}$ & $\begin{array}{c}54 \\
(33.54 \%)\end{array}$ & $\begin{array}{c}64 \\
(55.65 \%)\end{array}$ & $\begin{array}{c}41 \\
(28.08 \%)\end{array}$ & $\begin{array}{c}68 \\
(42.24 \%)\end{array}$ \\
\hline 3 & $\begin{array}{c}22 \\
(19.13 \%)\end{array}$ & $\begin{array}{c}7 \\
(4.79 \%)\end{array}$ & $\begin{array}{c}23 \\
(14.29 \%)\end{array}$ & $\begin{array}{c}18 \\
(15.65 \%)\end{array}$ & $\begin{array}{c}7 \\
(4.79 \%)\end{array}$ & $\begin{array}{c}13 \\
(8.07 \%)\end{array}$ \\
\hline $\mathrm{N}$ & $\begin{array}{c}115 \\
(100 \%) \\
\end{array}$ & $\begin{array}{c}146 \\
(100 \%) \\
\end{array}$ & $\begin{array}{c}161 \\
(100 \%) \\
\end{array}$ & $\begin{array}{c}115 \\
(100 \%) \\
\end{array}$ & $\begin{array}{c}146 \\
(100 \%) \\
\end{array}$ & $\begin{array}{c}161 \\
(100 \%)\end{array}$ \\
\hline \multicolumn{7}{|c|}{ p-values from $\chi^{2}$ goodness-of-fit tests } \\
\hline \multicolumn{7}{|c|}{ p-values from two-sided Binomial tests } \\
\hline 0 correct guess & 0.004 & 0.454 & 0.721 & $<0.001$ & 0.258 & 1 \\
\hline 1 correct guess & 0.565 & 0.494 & 0.371 & 0.012 & 0.001 & 1 \\
\hline 2 correct guesses & 0.386 & 0.494 & 0.329 & $<0.001$ & 0.021 & 0.222 \\
\hline 3 correct guesses & 0.046 & 0.002 & 0.475 & 0.321 & 0.002 & 0.095 \\
\hline Percent earn worst & $39.13 \%$ & $4.79 \%$ & NA & $2.61 \%$ & $32.87 \%$ & NA \\
\hline Expected percent & $50.00 \%$ & $12.50 \%$ & & $12.50 \%$ & $50.00 \%$ & \\
\hline Percent earn not best & $80.87 \%$ & $45.20 \%$ & NA & $28.70 \%$ & $84.24 \%$ & NA \\
\hline Expected percent & $87.50 \%$ & $50.00 \%$ & & $50.00 \%$ & $87.50 \%$ & \\
\hline \multicolumn{7}{|c|}{ Mean percent of subjects lying to avoid } \\
\hline - the worst outcome & 21.24 & 59.62 & $8.33^{\mathrm{a}}$ & 77.65 & 33.79 & $5.16^{\mathrm{a}}$ \\
\hline * lower bound CI & 6.43 & 37.86 & 0 & 63.59 & 22.13 & 0 \\
\hline * upper bound CI & 34.35 & 74.00 & 27.15 & 86.47 & 43.76 & 14.93 \\
\hline - any bad outcome & 7.61 & 10.71 & $7.32^{\mathrm{b}}$ & 42.10 & 4.25 & $2.00^{\mathrm{b}}$ \\
\hline * lower bound CI & 1.70 & 0 & 0 & 30.47 & 0 & 0 \\
\hline * upper bound CI & 13.69 & 22.94 & 18.30 & 51.84 & 9.47 & 6.07 \\
\hline
\end{tabular}

Notes: For Support conditions, the 'worst' outcome is to give $\$ 0$ and a 'bad' (or not best) outcome is to give less than $\$ 8$. For Oppose conditions, the 'worst' outcome is to give $\$ 8$ and a 'bad' outcome is to give anything greater than $\$ 0$. For the Other category ("independents" and "others"), there is no obvious best or worst outcome. Thus, we estimate the mean percent of subjects lying as follows: ${ }^{a}$ lying to avoid giving $\$ 8$ to a party, ${ }^{b}$ lying to avoid giving anything to a party.

Although not central to our core loss aversion prediction, we first test whether lying is higher amongst people who support or oppose a cause than amongst those who are not affiliated with either party to assess whether people lie for or against a cause they care about. This is confirmed by the $p$ values from $\chi^{2}$ goodness-of-fit tests and by the lower bounds of the $95 \%$ confidence intervals in 
Table 4: for the independent subjects, the empirical distribution of reports almost never differs significantly from the theoretical distribution. In contrast, the reports of partisans differ from the distribution expected if subjects reported honestly in a majority of cases. ${ }^{34}$

Our model predicts that people who support the party they are matched with will be more willing to lie to avoid earning $\$ 0$ for this party in the 0188 treatment than in the 0018 treatment; and that people who oppose the party they are matched with will be more willing to lie to avoid giving $\$ 8$ in the 0018 treatment than in the 0188 treatment. The data confirm this prediction.

Result 2. Consistent with our loss aversion model, individuals lie more to support a cause when the less desired outcome is more unlikely. The same directional effect is found when individuals oppose a cause.

Support for Result 2. As a complement to Table 4, Figures 5A and 5B show the mean estimated lying rates and confidence intervals when lying to avoid the worst outcome (i.e. giving $\$ 0$ to the party one supports, or $\$ 8$ to the party one opposes) and when lying to avoid a bad outcome/get the best outcome (i.e. giving $\$ 8$ to the party one supports, or $\$ 0$ to the party one opposes), respectively. The right two bars show the lying rate when subjects are paired with the party they oppose and the left two bars show the lying rate when subjects are paired with the party they support. The light bars represent the case when the worst outcome is likely and the dark bars the case when the worst outcome is unlikely.

Table 4 and Figure 5 show that for those subjects who support the party they are matched with, the estimated lying rate is significantly higher when observing the worst or a bad outcome is more unlikely ( $77.65 \%$ and $42.10 \%$, respectively) than when it is more likely $(21.24 \%$ and $7.61 \%$, respectively). That is, there is approximately a 56 percentage point increase in lying when observing

\footnotetext{
${ }^{34}$ Note that we also do not find any significant difference in the reported number of correct predictions between the subjects who declare an affiliation to the Democratic party and those who declare an affiliation to the Republican party (Kolmogorov-Smirnov tests of equality of distribution of reported outcomes, 0018 treatment: $p=0.951$ when subjects are matched with their preferred party and $p=0.780$ when they are mismatched; 0188 treatment: $p=0.675$ when subjects are matched with their preferred party and $p=0.987$ when they are mismatched).
} 
the worst outcome is more unlikely than when observing it is more likely $(77.65 \%-21.24 \%)$ and a $35 \%$ percentage point increase in lying when the bad outcome is more unlikely than when it is more likely $(42.10 \%-7.61 \%)$. These differences are significant at least at the $p<0.05(1-0.975 * 0.975)$ level since at least $97.5 \%$ of the two distributions in each comparison do not overlap.

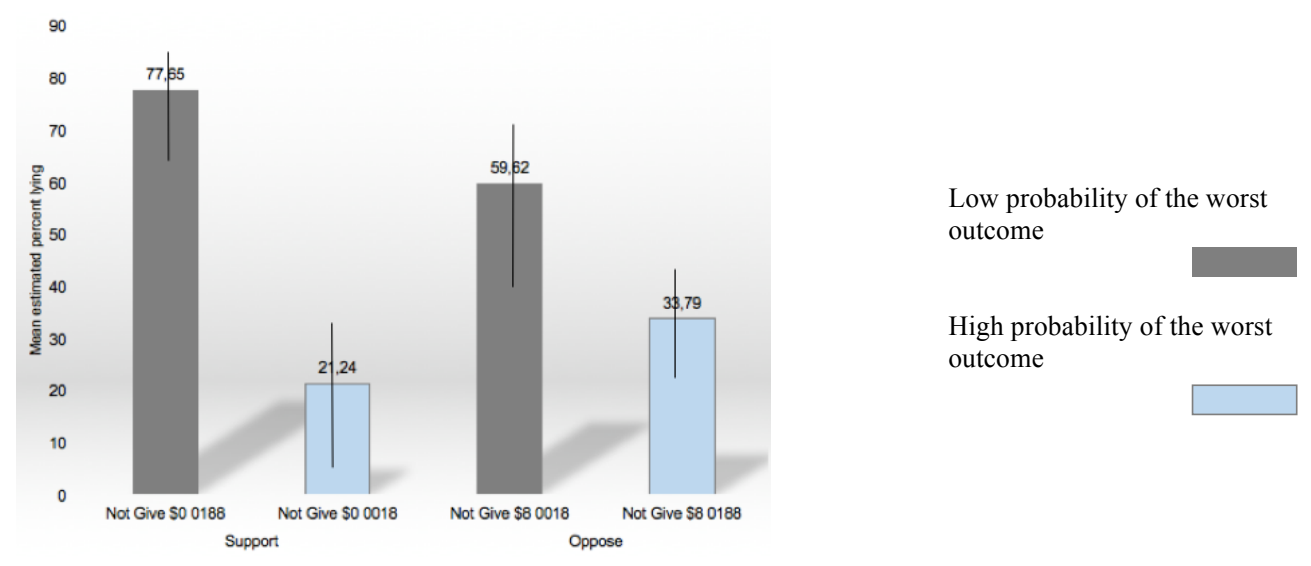

Figure 5A. Mean estimated percent lying to avoid the worst outcome, Study 2

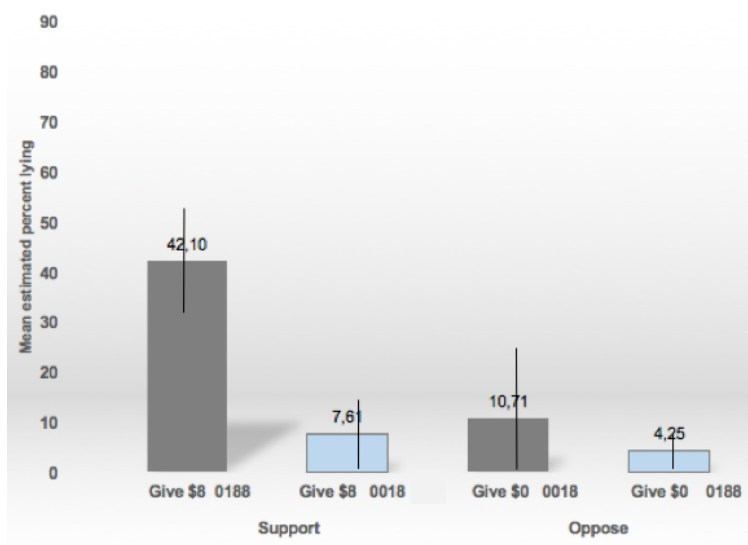

Low probability of the bad outcome

High probability of the bad outcome

Figure 5B. Mean estimated lying rates to avoid a bad outcome/get the best outcome, Study 2

For those who were paired with the party they oppose, the lying rate is again higher when the worst or a bad outcome is more unlikely $(59.62 \%$ and $10.71 \%$, respectively) than when it is more likely (33.79\% and $4.25 \%$, respectively). That is, there is approximately a 26 percentage point increase in lying when the worst outcome is more unlikely than when it is more likely $(59.62 \%$ $33.79 \%$ ) and a $6 \%$ percentage point increase when the bad outcome is more unlikely than when it is more likely $(10.71 \%-4.25 \%)$. When the worst outcome is more unlikely $(\mathrm{EV}=59.62)$, the lower 
bound on the $90 \%$ confidence interval is $43.36 \%$ and when it is more likely ( $\mathrm{EV}=33.79 \%$ ) the upper bound on the $90 \%$ confidence interval is $42.49 \%$. This difference is significant at least at the $p<0.10$ $(1-0.95 * 0.95)$ level since $95 \%$ of the two distributions do not overlap. However, we cannot reject that there is no statistical difference when the bad outcome is more unlikely $(\mathrm{EV}=10.71 \%)$ than when it is more likely $(\mathrm{EV}=4.25 \%)$ since even the tails of the $60 \%$ confidence intervals overlap each other.

Overall, these results support our main hypothesis that people will lie more the less likely the probability of the bad outcome when lying to support or avoid supporting a cause. They also suggest that people are less sensitive to the outcome's likelihood when lying to avoid giving money to a cause they oppose than when giving to a cause one supports. ${ }^{35}$

\section{Discussion and conclusion}

Loss aversion predicts that the probability of observing each payoff outcome affects the level of dishonesty. In this paper, we demonstrate theoretically that as the likelihood of observing an ex-ante low payoff outcome decreases, the gain in utility for a loss-averse agent who reports dishonestly to avoid the loss increases. We also develop a simple econometric technique to estimate the full distribution of dishonesty, which gives us a precise estimate of the mean lying rate, confidence intervals and any other statistic one can obtain from the CDF. We use this technique to analyze data from the extant literature and two new experiments to confirm that individuals lie more to avoid the undesired outcome when the undesired outcome is more unlikely to be observed.

\footnotetext{
${ }^{35}$ A Kolmogorov-Smirnov test concludes that the distribution of reported outcomes differs between subjects who support the party they are paired with in the 0188 treatment and the subjects who oppose the party they are paired with in the 0018 treatment $(p=0.045)$. A Mann-Whitney rank-sum test shows that the reports are higher when subjects support than when they oppose $(p=0.024)$ the party they are paired with. In contrast, both a Kolmogorov-Smirnov test and a MannWhitney test indicate that there is no difference in reports between subjects who support the party they are paired with in the 0018 treatment and the subjects who oppose the party they are paired with in the 0188 treatment $(p=0.950$ and $p=0.702$, respectively). To compare the values between supporters and opponents in these tests, we transform the reports of the subjects who oppose the party they are matched with (for example, 0 reported correct prediction in 0188 for opponents is coded 4 , so that it can be compared to 4 correct predictions by supporters in the 0018 treatment).
} 
Of course, several extensions of our study can be thought of. For example, regarding the measurement of lying behavior, we could also consider a Bayesian approach and allow for priors, which may tighten the distribution of dishonesty. We could also allow for decision errors, which would add more noise. To further test the theoretical model, new experiments could measure each subject's degree of loss and risk aversion to more directly explore the relationship between loss aversion and lying. ${ }^{36}$ Moreover, the role of loss aversion and reference-dependence does not exclude the influence of other factors that may motivate people to lie more when a bad payoff outcome is more unlikely. For example, Gneezy et al., (2016) and Dufwenberg and Dufwenberg (2016) present models in which a decision maker derives disutility based on the degree to which he is perceived to cheat (i.e., reputation concerns). In particular, if subjects perceive potential suspicion by the experimenter, they may be more likely to cheat when the bad outcome is rare (for example in our task, by reporting at least one correct guess when only zero correct guesses pays nothing) than when it is more likely (for example, reporting four correct guesses when less than four guesses pays nothing). Although we cannot exclude that some participants have a distaste for being perceived as acting suspicious in the extant literature, our experiments eliminate this concern. By conducting the studies online and double-anonymous, our experiment excludes any direct contact with, and any possibility of being observed by, the experimenter to minimize the salience that could possibly generate suspicion or risk of negative reputation if lying. Moreover, using a mind game guarantees that a lie cannot be detected at the individual level even if someone was observing the subject. Finally, in a post-experimental questionnaire, we asked subjects what they believed the aim of the experiment was. We examined the correlation between the subjects' answer and their payoff. While a

\footnotetext{
${ }^{36}$ There were a few reasons we did not measure risk aversion and loss aversion in this study. First, the length of our study was already approaching the average time for running MTurk studies, and to appropriately estimate risk and loss aversion would go beyond the upper limits of an MTurk study. Second, our estimate of lying is at the treatment level, thus we would either need to collect many more observations per subject or develop an alternative approach to estimate lying at the individual level. Third, we were concerned that measuring loss or risk aversion before our lying task might affect the lying task behavior and that performing the lying task first might affect the measure of risk and loss aversion.
} 
fraction of subjects suspected that we were studying lying, this fraction does not differ significantly across treatments and the belief that the experiment is about lying does not correlate with earnings, which would be expected if people were acting based on their fear of suspicion. ${ }^{37}$ Future research could include explicit measurement or manipulations of suspicion to more fully test this explanation or test reputation concerns in the absence of loss aversion.

Our study has a number of implications, both for academics and for policy-makers. Regarding academic implications, future studies can use our statistical method to estimate the full distribution of lying to more accurately assess the rate of lying. Our analysis reveals the importance of controlling for the probability of low payoff outcomes when studying lying behavior. Finally, it suggests that if experimentalists want to study situations where dishonesty might not otherwise be too high, they should use a large sample and set a low probability for the bad outcome. Regarding policy implications, our results suggest that to limit lying, choices should be framed to increase the perceived likelihood of the undesired outcome. They also suggest that costly efforts of detection should be concentrated on situations in which the likelihood of a bad outcome is relatively low.

\footnotetext{
${ }^{37}$ In study $1,47.06 \%$ of the participants in the 0222 treatment believe that the experiment is about lying and $21.69 \%$ believe that it is about luck (the other interpretations are too diverse to be categorized on a single denomination). The respective percentages are $47.33 \%$ and $26.33 \%$ in the 0022 treatment, and $47.37 \%$ and $21.05 \%$ in the 0002 treatment. Pairwise comparisons show that these percentages are not significantly different $(p>0.1)$. We also estimated a logit model in which the dependent variable is the high payoff and the independent variables include the beliefs of the subjects about the aim of the experiment (studying lying, studying the role of luck, and others). We find that the belief that the experiment is about lying is not significantly correlated with earnings (details available upon request). Similarly in study $2,34.9 \%$ (34.8\%) of participants in the match (mismatch) treatment believe the experiment is about lying and $20.5 \%$ $(21.7 \%)$ believe it is about politics. Pairwise comparisons find these believes are not significantly different across treatments. Multinomial logit analyses show that whether people thought the study was about lying, politics or something else had no significant effect on the payout to the political parties (details available upon request). These results suggest that the salience of our interest in lying is not changing behavior, and thus it is unlikely that a fear of behaving suspiciously would explain the results.
} 


\section{References}

Abdellaoui, Mohammed, Han Bleichrodt, and Corina Paraschiv (2007). Loss Aversion Under Prospect Theory: A Parameter-Free Measurement, Management Science, 53: 1659-1674.

Abeler, Johannes, Anke Becker, and Armin Falk (2014). Representative evidence on lying costs. Journal of Public Economics, 113: 96-104.

Abeler, Johannes (2015). A reporting experiment with Chinese professionals. Mimeo.

Abeler, Johannes, Daniele Nosenzo, and Collin Raymond (2016). Preferences for truth-telling. IZA Discussion Paper, 10188, Bonn.

Amir, Amitai, Tehila Kogut, and Yoella Bereby-Meyer (2016). Careful Cheating: People Cheat Groups Rather than Individuals. Frontiers in Psychology, 7, article 371.

Antony, Markus, Armin Falk, and Holger Gerhardt (2016). The Impact of Food and Water Deprivation on Economic Decision-Making. Poster, Society for Neuroeconomics $13^{\text {th }}$ Annual Meeting, September, Miami.

Arbel, Yuval, Ronen Bar-El, Erez Siniver, and Yossef Tobol (2014). Roll a die and tell a lie-what affects honesty? Journal of Economic Behavior \& Organization, 107: 153-172.

Ariely, Dan, Ximena Garcia-Rada, Lars Hornuf, and Heather Mann (2014). The (true) legacy of two really existing economic systems. University of Munich Discussion Paper, 2014-26.

Aydogan, Gökhan, Andrea Jobst, Fabian Loy, Norbert Müller, and Martin Kocher (2015). Oxytocin promotes dishonesty under competition. Mimeo, University of Munich.

Banerjee, Ritwick, Nabanita Datta Gupta, and Marie Claire Villeval (2016). The spillover effects of Affirmative Action on confidence and unethical behavior. GATE Working Paper, November.

Barfort, Sebastian, Nikolai Harmon, Frederik Hjorth, and Asmus L. Olsen (2015). Dishonesty and Selection into Public Service in Denmark: Who Runs the World's Least Corrupt Public Sector? University of Copenhagen Discussion Paper.

Beck, Thorsten, Christopher Bühren, B. Frank, and Elina Khachatryan (2016). Lying in the face of monitoring, reciprocity, and commitment. Mimeo.

Becker, Gary S. (1968). Crime and punishment: An economic approach. Journal of Political Economy, 76: 169-217.

Blanco, Celia, Lara Ezquerra, and Ismael Rodriguez-Lara (2015). Incentives to cheat under loss aversion. Mimeo.

Blanco, Mariana, and Juan Camilo Cárdenas (2015). Honesty after a labor relationship. Universidad del Rosario Discussion Paper, 2015-37.

Braun, Susanne, and Lars Hornuf (2015). Leadership and persistency in spontaneous dishonesty. IAAEU Discussion Paper, 10/2015.

Bryan, Christopher J., Gabrielle S. Adams, and Benoît Monin (2013). When Cheating Would Make You a Cheater: Implicating the Self Prevents Unethical Behavior. Journal of Experimental Psychology: General, 142 (4): 1001-1005.

Bucciol, Alessandro, and Marco Piovesan (2011). Luck or cheating? A field experiment on honesty with children. Journal of Economic Psychology, 32 (1): 73-78. 
Cadsby, C. Bram, Ninghua Du, and Fei Song (2016). In-group favoritism and moral decisionmaking. Journal of Economic Behavior \& Organization, 128: 59-71.

Cameron, Jessica S., and Dale T. Miller (2009). Ethical Standards in Gain versus Loss Frames. In David de Cremer (Ed.), Psychological Perspectives on Ethical Behavior and Decision Making. Information Age Publishing, Charlotte, NC: 91-106.

Charness, Gary, David Masclet, and Marie Claire Villeval (2014). The dark side of competition for status. Management Science, 60 (1): 38-55.

Chytilova, Julie, and Vaclav Korbel (2014). Individual and group cheating behavior: a field experiment with adolescents. IES Working Paper, 06/2014.

Clot, Sophie, Gilles Grolleau, and Lisette Ibanez (2014). Smug Alert! Exploring self-licensing behavior in a cheating game. Economics Letters, 123 (2): 191-194.

Cohen, Taya R., Scott T. Wolf, Abigail T. Panter, and Chester A. Insko (2011). Introducing the GASP scale: a new measure of guilt and shame proneness. Journal of Personality and Social Psychology, 100 (5): 947.

Cohn, Alain, Ernst Fehr, and Michel André Maréchal (2014). Business culture and dishonesty in the banking industry. Nature, 516 (7529): 86-89.

Cohn, Alain, and Michel André Maréchal (2015). Laboratory Measure of Cheating Predicts School Misconduct. University of Zurich Working Paper, 205.

Cohn, Alain, Michel André Maréchal, and Thomas Noll (2015). Bad Boys: How Criminal Identity Salience Affects Rule Violation. Review of Economic Studies, 82 (4): 1289-1308.

Conrads, Julian (2014). The effect of communication channels on lying. Cologne Graduate School Working Paper, 5(6).

Conrads, Julian, Bernd Irlenbusch, Rainer Michael Rilke, Gari Walkowitz (2013). Lying and team incentives. Journal of Economic Psychology, 34: 1-7.

Dai, Zhixin, Fabio Galeotti, and Marie Claire Villeval (2016). Cheating in the Lab Predicts Fraud in the Field: An Experiment in Public Transportations. Forthcoming in Management Science.

Danilov, Anastasia, Torsten Biemann, Thom Kring, and Dirk Sliwka (2013). The dark side of team incentives: Experimental evidence on advice quality from financial service professionals. Journal of Economic Behavior \& Organization, 93: 266-272.

Darke, Peter R., and Jonathan L. Freedman (1997). The belief in good luck scale. Journal of Research in Personality, 31 (4): 486-511.

Dato, Simon, and Petra Nieken (2015). Compensation and Honesty: Gender Differences in Lying. Discussion Paper Series in Economics and Management, 15-20.

Dieckmann, Anja, Urs Fischbacher, Veronika Grimm, Matthias Unfried, Verena Utikal, and Lorenzo Valmasoni (2015). Trust and Beliefs Among Europeans: Cross-country Evidence on Perceptions and Behavior. IWQW Discussion Paper, 04/2015.

Diekmann, Andreas, Wojtek Przepiorka, and Heiko Rauhut (2015). Lifting the veil of ignorance: An experiment on the contagiousness of norm violations. Rationality and Society, 27 (3): 309-333. 
di Falco, Salvatore, Brice Magdalou, David Masclet, Marie Claire Villeval, and Marc Willinger (2016). Can transparency of information reduce embezzlement? An experiment in Tanzania. IZA Discussion Paper, 9925, Bonn.

Djawadi, Behnud Mir, and René Fahr (2015). “. . . and they are really lying”: Clean evidence on the pervasiveness of cheating in professional contexts from a field experiment. Journal of Economic Psychology, 48: 48-59.

Drupp, Morotz A., Menusch Khadjavi, and Martin F. Quaas (2016). Truth-Telling and the Regulator. Evidence from a Field Experiment with Commercial Fishermen. Mimeo.

Dufwenberg, Martin Jr., and Martin Dufwenberg Sr (2016). Lies in Disguise - A theoretical Analysis of Cheating, Working Paper.

Eckel, Catherine C., and Philip J. Grossman (2008). Men, women and risk aversion: Experimental evidence. in Charles Plott and Vernon Smith (Eds.), Handbook of Experimental Economics Results, New York, Elsevier, 1, chapter 113: 1061-1073.

Effron, Daniel A., Christopher J. Bryan, and J. Keith Murnighan (2015). Cheating at the End to Avoid Regret. Journal of Personality and Social Psychology, 109 (3): 395-414.

Falk, Armin, and James Heckman (2009). Lab Experiments are a Major Source of Knowledge in the Social Sciences. Science, 326 (5952): 535-538.

Faravelli, Marco, Lana Friesen, and Lata Gangadharan (2015). Selection, tournaments, and dishonesty. Journal of Economic Behavior \& Organization, 110:160-175.

Fischbacher, Urs, and Franziska Föllmi-Heusi (2013). Lies in disguise - an experimental study on cheating. Journal of the European Economic Association, 11 (3): 525-547.

Foerster, Anna, Roland Pfister, Constantin Schmidts, David Dignath, and Wilfried Kunde (2013). Honesty saves time (and justifications). Frontiers in Psychology, 4 (473): 1-2.

Fosgaard, Toke Reinholt, Lars Gaarn Hansen, and Marco Piovesan (2013). Separating Will from Grace: An experiment on conformity and awareness in cheating. Journal of Economic Behavior \& Organization, 93: 279-284.

Gächter, Simon, and Jonathan F. Schulz (2016). Intrinsic honesty and the prevalence of rule violations across societies. Nature, 531, 24 March: 496-499.

Gneezy, Uri, Alexandre Imas, and Kristóf Madarász (2014). Conscience Accounting: Emotion Dynamics and Social Behavior. Management Science 60 (11), 2645-2658.

Gneezy, Uri, Agne Kajackaite and Joel Sobel (2016). Lying Aversion and the Size of the Lie. SSRN working paper.

Grolleau, Gilles, Martin G. Kocher, and Angela Sutan (2016). Cheating and loss aversion: do people lie more to avoid a loss? Forthcoming in Management Science.

Halevy, Rony, Shaul Shalvi, and Bruno Verschuere (2013). Being Honest About Dishonesty: Correlating Self-Reports and Actual Lying. Human Communication Research, 40 (1): 54-72.

Hanna, Rema, and Shing-Yi Wang (2013). Dishonesty and Selection into Public Service. NBER Working Paper, 19649.

Hilbig, Benjamin E., and Corinna M. Hessler (2013). What lies beneath: How the distance between truth and lie drives dishonesty. Journal of Experimental Social Psychology, 49 (2): 263-266. 
Hilbig, Benjamin E., and Ingo Zettler (2015). When the cat's away, some mice will play: A basic trait account of dishonest behavior. Journal of Research in Personality, 57: 72-88.

Holt, Charles A., and Susan K. Laury (2002). Risk aversion and incentive effects. American Economic Review, 92 (5): 1644-1655.

Horton, John J., David G. Rand, and Richard J. Zeckhauser (2011). The online laboratory: conducting experiments in a real labor market. Experimental Economics, 14 (3): 399-425.

Houser, Daniel, John A. List, Marco Piovesan, Anya Samek, and Joachim Winter (2016). Dishonesty: From parents to children. European Economic Review, 82: 242-254.

Hruschka, Daniel, Charles Efferson, Ting Jiang, Ashlan Falletta-Cowden, Sveinn Sigurdsson, Rita McNamara, Madeline Sands, Shirajum Munira, Edward Slingerland, and Joseph Henrich (2014). Impartial Institutions, Pathogen Stress and the Expanding Social Network. Human Nature, 25 (4):567-579.

Huber, Stefan, and Odilo W. Huber (2012). The centrality of religiosity scale (CRS). Religions, 3.3: 710-724.

Hugh-Jones, David (2016). Honesty, beliefs about honesty, and economic growth in 15 countries. Journal of Economic Behavior \& Organization, 127: 99-114.

Irlenbusch, Bernd, and Marie Claire Villeval (2015). Behavioral ethics: how psychology influenced economics and how economics might inform psychology? Current Opinions in Psychology, 6, 87-92.

Jacob, Brian A., and Steven D. Levitt (2003). Rotten apples: an investigation of the prevalence and predictors of teacher cheating. Quarterly Journal of Economics, 118: 843-877.

Jacobsen, Catrine, and Marco Piovesan (2016). Tax me if you can: An artefactual field experiment on dishonesty. Journal of Economic Behavior \& Organization, 124: 7-14.

Jiang, Ting (2013). Cheating in mind games: The subtlety of rules matters. Journal of Economic Behavior \& Organization, 93: 328-336.

Jiang, Ting (2015). Other-regarding Preferences and Other-regarding Cheating - Experimental Evidence from China, Italy, Japan and the Netherlands. Mimeo.

Kajackaite, Agne, and Uri Gneezy (2015). Lying costs and incentives. UC San Diego Discussion Paper.

Kahneman, Daniel, and Amos Tversky (1979). Prospect Theory: An Analysis of Decision Under Risk. Econometrica, 47: 263-291.

Kahneman, Daniel, and Amos Tversky (1992). Advances in Prospect Theory: Cumulative Representation of Uncertainty. Journal of Risk and Uncertainty, 5: 297-323.

Kroher, Martina, and Tobias Wolbring (2015). Social control, social learning, and cheating: Evidence from lab and online experiments on dishonesty. Social Science Research, 53: 311-324.

Krupka, Erin L., and Roberto A. Weber (2013). Identifying social norms using coordination games: why does dictator game sharing vary? Journal of the European Economic Association, 11 (3): 495-524. 
Lewis, Alan, Alexander Bardis, Chloe Flint, Claire Mason, Natalya Smith, Charlotte Tickle, and Jennifer Zinser (2012). Drawing the line somewhere: An experimental study of moral compromise. Journal of Economic Psychology, 33 (4), 718-725.

Lundquist, Tobias, Ellingsen, Tor, Gribbe, Erik, and Johannesson, Magnus (2009). The aversion to lying. Journal of Economic Behavior \& Organization, 70, 81-92.

Mann, Heather, Ximena Garcia-Rada, Lars Hornuf, Juan Tafurt, and Dan Ariely (2016). Cut From the Same Cloth: Similarly Dishonest Individuals Across cultures. Journal of Cross-Cultural Psychology, 47 (6): 858-874.

Mazar, Nina, Amir, O., and Dan Ariely (2008). The dishonesty of honest people: A theory of selfconcept maintenance. Journal of Marketing Research, 45, 633-644.

Meub, Lukas, Till Proeger, Tim Schneider, and Kilian Bizer (2015). The victim matters Experimental evidence on lying, moral costs and moral cleansing. CEGE Discussion Papers, 233.

Muehlheusser, Gerd, Andreas Roider, and Niklas Wallmeier (2015). Gender differences in honesty: Groups versus individuals. Economics Letters, 128: 25-29.

Muñoz-Izquierdo, Nora, Beatriz Gil-Gómez de Liaño, Francisco Daniel Rin-Sánchez, and David Pascual-Ezama (2014). Economists: cheaters with altruistic instincts. MPRA Discussion Paper, Jena.

Paolacci, Gabriele, Jesse Chandler, and Panagiotis G. Ipeirotis (2010). Running experiments on Amazon Mechanical Turk. Judgment and Decision Making 5 (5):411-419.

Pascual-Ezama, David, Fosgaard, Toke R., Juan Camilo Cardenas, Praveen Kujal, Robert Veszteg, Beatriz Gil-Gómez de Liaño, Brian Gunia, Doris Weichselbaumer, Katharina Hilken, Armenak Antinyan, Joyce Delnoij, Antonios Proestakis, Michael D. Tira, Yulius Pratomo, Tarek JaberLopez, and Pablo Branas-Garza (2015). Context-dependent cheating: Experimental evidence from 16 countries. Journal of Economic Behavior \& Organization, 116: 379-386.

Ploner, Matteo, and Tobias Regner (2013). Self-image and moral balancing: An experimental analysis. Journal of Economic Behavior \& Organization, 93: 374-383.

Potters, Jan, and Jan Stoop (2016). Do cheaters in the lab also cheat in the field? European Economic Review, 87: 26-33.

Rauhut, Heiko (2013). Beliefs about Lying and Spreading of Dishonesty: Undetected Lies and Their Constructive and Destructive Social Dynamics in Dice Experiments. PLoS One, 8 (11).

Rosenbaum, Stephen Mark, Stephan Billinger, and Nils Stieglitz (2014). Let's be honest: A review of experimental evidence of honesty and truth-telling. Journal of Economic Psychology, 45, 181196.

Ruffle, Bradley J., and Yossef Tobol (2014). Honest on mondays: Honesty and the temporal separation between decisions and payoffs. European Economic Review, 65: 126-135.

Ruffle, Bradley J., and Yossef Tobol (2015). Clever enough to tell the truth. LCERPA Working Paper, 2015-12.

Schindler, Simon, and Stefan Pfattheicher (2016). The frame of the game: Loss-framing increases dishonest behavior. Journal of Experimental Social Psychology, forthcoming.

Shalvi, Shaul (2012). Dishonestly increasing the likelihood of winning. Judgment and Decision Making, 7 (3): 292-303. 
Shalvi, Shaul, Jason Dana, Michel J.J. Handgraaf, and Carsten K.W. de Dreu (2011). Justified ethicality: Observing desired counterfactuals modifies ethical perceptions and behavior. Organizational Behavior and Human Decision Processes, 115 (2): 181-190.

Shalvi, Shaul, Ori Eldar, and Yoella Bereby-Meyer (2012). Honesty Requires Time (and Lack of Justifications). Psychological Science, 23 (10): 1264-1270.

Shalvi, Shaul, and David Leiser (2013). Moral firmness. Journal of Economic Behavior \& Organization, 93: 400-407.

Shalvi, Shaul, and Carsten K.W. de Dreu (2014). Oxytocin promotes group-serving dishonesty. Proceedings of the National Academy of Sciences, 111 (15): 5503-5507.

Shen, Qiang, Meijun Teo, Eyal Winter, Einav Hart, Soo H. Chew, and Richard P. Ebstein (2016). To Cheat or Not To Cheat: Tryptophan Hydroxylase 2 SNP Variants Contribute to Dishonest Behavior. Frontiers in Behavioral Neuroscience, 10: 82.

Škoda, Samuel (2013). Effort and cheating behavior: An experiment. Bachelor Thesis. Charles University in Prague.

Suri, Siddharth, Daniel G. Goldstein, and Winter A. Mason (2011). Honesty in an Online Labor Market. Human Computation: Papers from the 2011 AAAI Workshop (WS-11-11): 61-66.

Suri, Siddharth, and Duncan J. Watts (2011). Cooperation and Contagion in Web-Based, Networked Public Goods Experiments. PLoS One, 6 (3).

Thielmann, Isabel, Benjamin E. Hilbig, Ingo Zettler, and Morten Moshagen (2016). On Measuring the Sixth Basic Personality Dimension: A Comparison Between HEXACO Honesty-Humility and Big Six Honesty-Propriety. Assessment: 1-13.

Utikal, Verena, and Urs Fischbacher (2013). Disadvantageous lies in individual decisions. Journal of Economic Behavior \& Organization, 85: 108-111.

Waubert De Puiseau, Berenike, and Andreas Glöckner (2012). Investigating Cheating Behavior in Students Compared to the General Public. Poster.

Weisel, Ori, and Shaul Shalvi (2015). The collaborative roots of corruption. Proceedings of the National Academy of Sciences, 112 (34): 10651-10656.

Wibral, Matthias, Thomas Dohmen, Dietrich Klingmüller, Bernd Weber, and Armin Falk (2012). Testosterone Administration Reduces Lying in Men. PLoS One, 7 (10).

Zettler, Ingo, Benjamin E. Hilbig, Morten Moshagen, and Reinout E. de Vries (2015). Dishonest responding or true virtue? A behavioral test of impression management. Personality and Individual Differences, 81: 107-111.

Zimerman, Liora, Shaul Shalvi, and Yoella Bereby-Meyer (2014). Self-reported ethical risk taking tendencies predict actual dishonesty. Judgment and Decision Making, 9 (1): 58-64. 


\section{Supplementary Materials for:}

Loss aversion and lying behavior: Theory, estimation and empirical evidence

\section{Contents}

Instructions:

Experiment 1: Lying for self with vary probability of gain instructions (web link accessible as of 06/12/2016 https://az1.qualtrics.com/ControlPanel/?ClientAction=EditSurvey\&Section=SV_bI9ZO3D013 uo61 $\&$ SubSection $=\&$ SubSubSection $=\&$ PageActionOptions $=\&$ TransactionID $=1 \&$ Repeatabl $\mathrm{e}=0$ )

Experiment 2: Lying to support or avoid supporting an organization instructions

(web link accessible as of 06/12/2016

https://az1.qualtrics.com/ControlPanel/?ClientAction=EditSurvey\&Section=SV_ac4TD3rGA

3 HZALr\&SubSection $=\&$ SubSubSection $=\&$ PageActionOptions $=\&$ TransactionID $=1 \&$ Repeata ble $=0$ )

Tables:

Table A1: List of papers included in our review

Table A2. Exogenous characteristics of participants

Table A3: Study 1 Logistic Regression: Influence of Possible Covariates on Payout

Table A4: Study 2 Ordinal Logistic Regression: Influence of Possible Covariates on Payout 


\section{Instructions for Experiment 1: Lying for self with vary probability of gain}

\section{Overview:}

In addition to your normal pay for completing the task, you can get additional money for yourself. At the completion of this experiment, we will bonus you for any additional money you make. While the base pay for completing the task is modest, you might potentially get significant extra money.

How you will generate extra money:

The task involves predicting coin flips. The results of this coin flip will determine your extra pay.

Coin toss task:

You will be asked to toss a coin three times. If you do not have a coin at this time, please get a coin before proceeding to the next page.

Tossing the coin:

When you toss the coin, let it land on a flat surface so that one side of the coin is clearly facing-up and the other side is clearly facing-down.

Predicting the outcome of each coin toss:

Before each toss, predict which side of the coin will be face-up. To make your prediction, we would like you to make your prediction out loud before each coin toss. Thus, you can make just one of two possible predictions:

"I predict Heads will be face-up" Or

"I predict Tails will be face-up."

Recording the outcome of your prediction:

In this task you will toss a coin a total of three times and report how many times you correctly predicted the coin toss. If you correctly predict the coin toss all three times, then report 3 . If you correctly predict the coin toss twice, then report 2 . If you correctly predict the coin toss just once, then report 1. And if you do not correctly predict any of the three coin tosses, then report 0 .

Note that it does not matter in which order you make correct or incorrect predictions. For instance, if you correctly predicted the first toss only, or the second toss only, or the third toss only, then in all these cases you would report 1 .

Valuing each correct prediction:

Depending on the outcome of your coin tosses you can get a $\$ 2$ bonus payment.

The page will indicate how much you can get for each correct prediction. There will be an amount listed for getting 0 correct predictions, 1 correct prediction, 2 correct predictions and 3 correct 
predictions. You will indicate your number of correct predictions by clicking on the appropriate option.

On this page we show you an example of how you will record the number of correct predictions. The payout schedule is shown below. This is only an example, the actual payout schedule may be different.

\section{Example:}

Click on the number of correct coin toss predictions

Payout Schedule:

$$
\begin{aligned}
& 0 \text { correct prediction - Gain } \$ 0 \text { additional reward } \\
& 1 \text { correct prediction - Gain } \$ 0 \text { additional reward } \\
& 2 \text { correct predictions - Gain } \$ 2 \text { additional reward } \\
& 3 \text { correct predictions - Gain } \$ 2 \text { additional reward }
\end{aligned}
$$

You will thus only click on the number of correct predictions, and then click next to move to the next page.

\section{Getting started:}

If you have not done so yet, please get a coin. We would like you to not take any breaks while completing the rest of the task, so when you are ready, please continue to the prediction page and additional survey questions.

\section{Prediction page differed between subject conditions}

\section{Prediction Page (0002 condition):}

Please complete your three coin tosses now and click on the number of correct coin toss predictions. Depending on your outcome, you will receive payment of the amount listed.

$$
\begin{array}{ll}
0 & 0 \text { correct prediction - Gain } \$ 0 \text { additional reward (1) } \\
& 1 \text { correct prediction - Gain } \$ 0 \text { additional reward (2) } \\
\bigcirc & 2 \text { correct predictions - Gain } \$ 0 \text { additional reward (3) } \\
0 & 3 \text { correct predictions - Gain } \$ 2 \text { additional reward (4) }
\end{array}
$$

Prediction Page (0022 condition):

Please complete your three coin tosses now and click on the number of correct coin toss predictions. Depending on your outcome, you will receive payment of the amount listed.

$$
\begin{array}{ll}
0 & 0 \text { correct prediction - Gain } \$ 0 \text { additional reward (1) } \\
0 & 1 \text { correct prediction - Gain } \$ 0 \text { additional reward (2) } \\
& 2 \text { correct predictions - Gain } \$ 2 \text { additional reward (3) } \\
& 3 \text { correct predictions - Gain } \$ 2 \text { additional reward (4) }
\end{array}
$$

\section{Prediction Page (0222 condition):}

Please complete your three coin tosses now and click on the number of correct coin toss predictions. Depending on your outcome, you will receive payment of the amount listed.

$$
\begin{array}{ll}
0 & 0 \text { correct prediction - Gain } \$ 0 \text { additional reward (1) } \\
\bigcirc & 1 \text { correct prediction - Gain } \$ 2 \text { additional reward (2) } \\
\bigcirc & 2 \text { correct predictions - Gain \$2 additional reward (3) } \\
0 & 3 \text { correct predictions - Gain \$2 additional reward (4) }
\end{array}
$$

Before we move on to the attitude and demographic questions, we would like to give you one more chance to earn more money for yourself. Like you, other participants in this study are reporting the outcomes of coin 
tosses to earn money. We would like you to evaluate whether reporting more, less or the actual amount of money earned is "socially appropriate" and "consistent with moral or proper social behavior," or are "socially inappropriate" and "inconsistent with moral or proper social behavior." By socially appropriate, we mean behavior that most people agree is the "correct" or "ethical" thing to do. Another way to think about what we mean is that if the participant was to select a socially inappropriate choice, then someone else might be judgmental of this person for doing so. Please answer each question as accurately as possible, based on your opinion of what constitutes socially appropriate or socially inappropriate behavior. At the end of the experiment, we will randomly select one participant and one of the four questions below. If you are chosen and gave the same response to the question that is most frequently given by all other participants, then you will receive an additional $\$ 100$ as a bonus to your MTurk account.

How socially appropriate or inappropriate is it to report...

\begin{tabular}{|c|c|c|c|c|}
\hline $\begin{array}{c}\text { Very Socially } \\
\text { Inappropriate } \\
(1)\end{array}$ & $\begin{array}{c}\text { Somewhat } \\
\text { Socially } \\
\text { Inappropriate } \\
(2)\end{array}$ & $\begin{array}{c}\text { Somewhat } \\
\text { Socially } \\
\text { Appropriate } \\
(3)\end{array}$ & $\begin{array}{c}\text { Very Socially } \\
\text { Appropriate } \\
(4)\end{array}$ \\
\hline $\begin{array}{c}\text { an outcome that earns } \$ 0 \text { when the } \\
\text { prediction would earn } \$ 0(4)\end{array}$ & 0 & 0 & 0 \\
$\begin{array}{c}\text { an outcome that earns } \$ 2 \text { when the } \\
\text { prediction would earn } \$ 0(1)\end{array}$ & 0 & 0 & 0 & 0 \\
$\begin{array}{c}\text { an outcome that earns } \$ 2 \text { when the } \\
\text { prediction would earn } \$ 2(2)\end{array}$ & 0 & 0 & 0 & 0 \\
\hline $\begin{array}{c}\text { an outcome that earns } \$ 0 \text { when the } \\
\text { prediction would earn } \$ 2(7)\end{array}$ & 0 & 0 & 0 \\
\hline
\end{tabular}

Before we finish, please complete the following set of questions about your experience, your views and yourself.

What type of coin did you use for the coin toss?

$\begin{array}{ll}\bigcirc & \text { Quarter (1) } \\ \bigcirc & \text { Dime (2) } \\ \bigcirc & \text { Nickel (3) } \\ \bigcirc & \text { Penny (4) } \\ \bigcirc & \text { Other (5) }\end{array}$

If you predicted three coins tosses correctly, how much extra money would you have earned?

$\begin{array}{ll}\mathrm{O} & \$ 1(1) \\ \mathrm{O} & \$ 2(2) \\ \mathrm{O} & \$ 4(3) \\ \mathrm{O} & \$ 8(4) \\ \mathrm{O} & \$ 10(5)\end{array}$


If we asked 1000 people to toss a coin three times, how many of them do you think would toss three heads? Please move the slide to your response (2)

How would you classify your political affiliation?

O Republican (1)

O Democratic (2)

Independent (3)

O Other (4)

How much do you agree with the goals of the Republican National Party?

Please move the slide to your response (1)

How much do you agree with the goals of the Democratic National Party?

Please move the slide to your response (1)

How often do you vote in national elections (including Senate, House of Representative, and Presidential elections)?

I never vote in national elections (1)

O I occasionally vote in national elections (2)

O I sometimes vote in national elections (3)

O I frequently vote in national elections (6)

I I usually vote in national elections (4)

I I always vote in national elections (5) 
Please indicate your level of agreement with the following statements $(1=$ Strongly disagree, $7=$ Strongly agree).

\begin{tabular}{|c|c|c|c|c|c|c|c|}
\hline & $\begin{array}{l}\text { Strongly } \\
\text { disagree } \\
\quad(1)\end{array}$ & $\begin{array}{l}\text { Disagree } \\
\text { (2) }\end{array}$ & $\begin{array}{l}\text { Somewhat } \\
\text { disagree } \\
\text { (3) }\end{array}$ & $\begin{array}{l}\text { Neither } \\
\text { agree nor } \\
\text { disagree } \\
\text { (4) }\end{array}$ & $\begin{array}{l}\text { Somewhat } \\
\text { agree (5) }\end{array}$ & $\begin{array}{l}\text { Agree } \\
\text { (6) }\end{array}$ & $\begin{array}{l}\text { Strongly } \\
\text { agree (7) }\end{array}$ \\
\hline $\begin{array}{l}\text { Luck plays an important part in } \\
\text { everyone's life. (1) }\end{array}$ & $\mathrm{O}$ & $\mathrm{O}$ & O & O & $\mathrm{O}$ & O & O \\
\hline $\begin{array}{l}\text { Some people are consistently lucky, and } \\
\text { others are unlucky. (2) }\end{array}$ & $\mathrm{O}$ & $\mathrm{O}$ & $\mathrm{O}$ & $\mathrm{O}$ & $\mathrm{O}$ & $\mathrm{O}$ & O \\
\hline $\begin{array}{l}\text { I consider myself to be a lucky person. } \\
\text { (3) }\end{array}$ & $\mathrm{O}$ & $\mathrm{O}$ & O & $\mathrm{O}$ & $\mathrm{O}$ & $\mathrm{O}$ & O \\
\hline I believe in luck. (4) & $\mathrm{O}$ & $\mathrm{O}$ & $\mathrm{O}$ & $\mathrm{O}$ & $\mathrm{O}$ & $\mathrm{O}$ & O \\
\hline I often feel like it's my lucky day. (5) & $\mathrm{O}$ & $\mathrm{O}$ & $\mathrm{O}$ & $\mathrm{O}$ & $\mathrm{O}$ & $\mathrm{O}$ & O \\
\hline I consistently have good luck. (6) & $\mathrm{O}$ & $\mathrm{O}$ & $\mathrm{O}$ & $\mathrm{O}$ & $\mathrm{O}$ & $\mathrm{O}$ & O \\
\hline $\begin{array}{l}\text { It's a mistake to base any decisions on } \\
\text { how lucky you feel. ( } 7 \text { ) }\end{array}$ & $\mathrm{O}$ & $\mathrm{O}$ & $\mathrm{O}$ & $\mathrm{O}$ & $\mathrm{O}$ & $\mathrm{O}$ & O \\
\hline Luck works in my favor. (8) & $\mathrm{O}$ & $\mathrm{O}$ & $\mathrm{O}$ & $\mathrm{O}$ & $\mathrm{O}$ & O & O \\
\hline $\begin{array}{l}\text { I don't mind leaving things to chance } \\
\text { because I'm a lucky person. (9) }\end{array}$ & $\mathrm{O}$ & 0 & 0 & 0 & 0 & 0 & 0 \\
\hline $\begin{array}{l}\text { Even the things in life I can't control } \\
\text { tend to go my way because I'm lucky. } \\
\text { (10) }\end{array}$ & 0 & 0 & 0 & 0 & 0 & 0 & 0 \\
\hline $\begin{array}{l}\text { There is such a thing as luck that favors } \\
\text { some people, but not others. (11) }\end{array}$ & 0 & 0 & 0 & 0 & 0 & 0 & 0 \\
\hline $\begin{array}{l}\text { Luck is nothing more than random } \\
\text { chance. (12) }\end{array}$ & 0 & 0 & 0 & 0 & 0 & 0 & 0 \\
\hline
\end{tabular}

And finally a few questions about yourself... What is your gender?

$$
\begin{array}{ll}
\bigcirc & \text { Male (1) } \\
\mathrm{O} & \text { Female (2) }
\end{array}
$$

What is your highest educational degree obtained?

$$
\begin{array}{ll}
\text { O } & \text { Primary school (1) } \\
\text { O } & \text { Less than high school (2) } \\
\text { O } & \text { High school diploma or equivalent (3) } \\
\text { O } & \text { Undergraduate degree (4) } \\
\text { O } & \text { Post-graduate degree (5) }
\end{array}
$$

What year were you born (e.g., 1980) (Dropdown box) 
What is your approximate household annual pretax income?

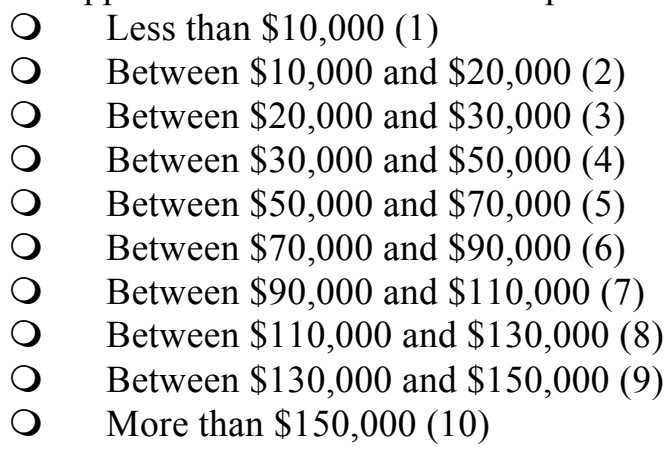

How much money do you spend in a typical week (this should be your daily expenses e.g., food, travel, mobile charges, purchases; but excluding rent, mortgage, educational fees, work expenses)?

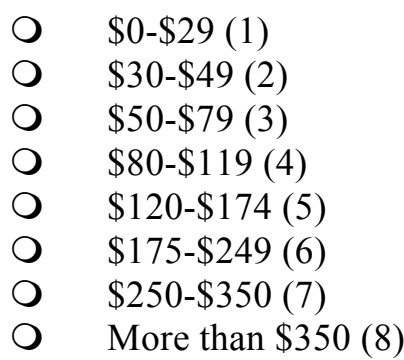

What do you think we are trying to assess with this study? (open-ended) 


\section{Instructions for Experiment 2: Lying to support or avoid supporting an organization}

Overview:

In this experiment, you will generate money for a political party. At the completion of this experiment, we will make a donation through the party's online donation page. The amount we will donate will be the sum of the amount that was generated by all participants who completed the study for the same political party. In a few pages, we will tell you which party you will be generating money for. First we will explain how you will generate money for the political party.

Generating money for the political party:

There will be 4 tasks that will affect the outcome. The first two task pages will involve predicting coin flips and the last two task pages will involve simple decisions. One of these four tasks will be randomly chosen to determine your donation. Each task is equally likely to be chosen. At the end of the study, we will show you which task was chosen and what your outcome was for that task, this will determine your individual donation. We will add all participants' outcomes at the end of the experiment and make a total donation.

Coin toss task:

On the following pages you will be asked to toss a coin three times. If you do not have a coin at this time, please get a coin before proceeding to the next page.

Tossing the coin:

When you toss the coin, let it land on a flat surface so that one side of the coin is clearly facing-up and the other side is clearly facing-down.

\section{Predicting the outcome of each coin toss}

Before each toss, predict which side of the coin will be face-up. To make your prediction, we would like you to make your prediction out loud before each coin toss. Thus, you can make just one of two possible predictions:

"I predict Heads will be face-up" Or

"I predict Tails will be face-up."

Recording the success of your prediction:

You will toss the coin a total of three times for each of the following pages, and on each page you will report how many times you correctly predicted the coin toss. If you correctly predict the coin toss all three times, then report 3 . If you correctly predict the coin toss twice, then report 2 . If you correctly predict the coin toss just once, then report 1 . And if you do not correctly predict any of the three coin tosses, then report 0.

Note that it does not matter in which order you make correct or incorrect predictions on each page. For instance, if you correctly predicted the first toss only, or the second toss only, or the third toss only, then in all these cases you would report 1.

\section{Value of each correct prediction:}

You will earn money for one of two political parties by correctly predicting the coin tosses. Each page will indicate how much you earn for each correct prediction. There will be an amount listed for getting 0 correct predictions, 1 correct prediction, 2 correct predictions and 3 correct predictions. You will indicate your number of correct predictions by clicking on the appropriate option.

On this page we show you an example of how you will record the number of correct predictions. The payout schedule is shown below. This is only an example, the actual payout schedule will be different for each task. 
Each page is for a separate set of three coin tosses. The donation amounts may vary between the two pages and for the number of correct predictions.

\section{Example}

Click on the number of correct coin toss predictions

Payout Schedule:

0 correct prediction - Earn $\$ 0$ for the party for this page

1 correct prediction - Earn $\$ 3$ for the party for this page

2 correct predictions - Earn $\$ 3$ for the party for this page

3 correct predictions - Earn $\$ 6$ for the party for this page

You will thus only click on the number of correct predictions, and then click next to move to the next page.

DNP 0018/0188 condition (DNP 0188/0018 condition same with the order of the prediction pages switched)

Political party you will generate money for:

You will either be randomly assigned (with equally probability) to generate money for the Democratic National Party or the Republican National Party.

The Democratic National Party's purpose is to advance the Democratic agenda and support Democratic candidates running for office. If you would like to learn more about this organization, please click on the following link that will open a new page on their home page https://www.democrats.org/about/our-party

The Republican National Party's purpose is to advance the Republican agenda and support Republican candidates running for office. If you would like to learn more about this organization, please click on the following link that will open a new page on their home page https://www.gop.com/platform/

You have been randomly assigned to generate money for the Democratic National Party. 
How do you feel about the Democratic National Party? (sliding scales from $-50-+50$ ) How much do you agree with the goals of this party? (1) How much do you want to help this party achieve their goals? (2)

How do you feel about the Republican National Party? (sliding scales from $-50-+50$ ) How much do you agree with the goals of this party? (1) How much do you want to help this party achieve their goals? (2)

\section{Summary:}

In this experiment, you will have two prediction pages each with three coin tosses. On each prediction page, you will toss a coin three times and make a prediction before each toss as to the outcome of the toss. You will then record how many tosses you correctly predicted of the three tosses. The page will also indicate how much will be donated to the Democratic National Party based on the number of correct predictions. The two coin toss tasks will be followed by the two decision tasks. One of these four tasks will be randomly selected with equal probability to determine the donation. At the end of the experiment, we will add or subtract the amount of money you have generated to the total money that we will send based on the outcome of all participants in this experiment.

\section{Getting started:}

If you have not done so yet, please get a coin. We would like you to not take any breaks while completing the two prediction pages, so when you are ready, please continue to the prediction pages.

Prediction Page 1:

Please complete three coin tosses now and click on the number of correct coin toss predictions. If this is the task selected for you, we will add the amount listed to the donation to the Democratic National Party.

\footnotetext{
O 0 correct prediction - Earn $\$ 0$ for the Democratic National Party (1)

O 1 correct prediction - Earn $\$ 0$ for the Democratic National Party (2)

O 2 correct predictions - Earn $\$ 1$ for the Democratic National Party (3)

O 3 correct predictions - Earn $\$ 8$ for the Democratic National Party (4)
}

\section{Prediction Page 2:}

Please complete three coin tosses now and click on the number of correct coin toss predictions. If this is the task selected for you, we will add the amount listed to the donation to the Democratic National Party.

$$
\begin{aligned}
& \text { O } 0 \text { correct prediction - Earn } \$ 0 \text { for the Democratic National Party (1) } \\
& \text { O } 1 \text { correct prediction - Earn } \$ 1 \text { for the Democratic National Party (2) } \\
& \text { O } 2 \text { correct predictions - Earn } \$ 8 \text { for the Democratic National Party (3) } \\
& \text { O } 3 \text { correct predictions - Earn } \$ 8 \text { for the Democratic National Party (4) }
\end{aligned}
$$

\section{Decision Task 1 (Democratic National Party):}

If this page is randomly selected, based on your choice below we will either add or subtract money from the donation to be made at the end of the study to the Democratic National Party.

\footnotetext{
Add $\$ 2$ to the total donation to the Democratic National Party (1)

Add nothing to the total donation to the Democratic National Party (2)

O Subtract \$2 from the total donation to the Democratic National Party (3)
} 


\section{Decision Task 2 (Republican National Party):}

If this page is randomly selected, based on your choice below we will either add or subtract money from the donation to be made at the end of the study to the Republican National Party.

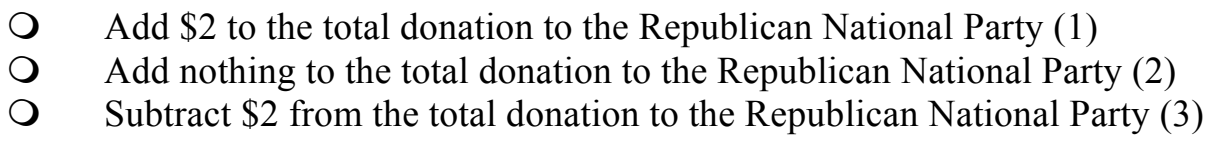

RNP 0018/0188 condition (RNP 0188/0018 condition same with the order of the prediction pages switched)

Political party you will generate money for:

You will either be randomly assigned (with equally probability) to generate money for the Democratic National Party or the Republican National Party.

The Democratic National Party's purpose is to advance the Democratic agenda and support Democratic candidates running for office. If you would like to learn more about this organization, please click on the following link that will open a new page on their home page https://www.democrats.org/about/our-party

The Republican National Party's purpose is to advance the Republican agenda and support Republican candidates running for office. If you would like to learn more about this organization, please click on the following link that will open a new page on their home page https://www.gop.com/platform/ You have been randomly assigned to generate money for the Republican National Party.

How do you feel about the Democratic National Party?

How much do you agree with the goals of this party? (1)

How much do you want to help this party achieve their goals? (2)

How do you feel about the Republican National Party?

How much do you agree with the goals of this party? (1)

How much do you want to help this party achieve their goals? (2)

\section{Summary:}

In this experiment, you will have two prediction pages each with three coin tosses. On each prediction page, you will toss a coin three times and make a prediction before each toss as to the outcome of the toss. You will then record how many tosses you correctly predicted of the three tosses. The page will also indicate how much will be donated to the Republican National Party based on the number of correct predictions. The two coin toss tasks will be followed by the two decision tasks. One of these four tasks will be randomly selected with equal probability to determine the donation. At the end of the experiment, we will add or subtract the amount of money you have generated to the total money that we will send based on the outcome of all participants in this experiment.

\section{Getting started:}

If you have not done so yet, please get a coin. We would like you to not take any breaks while completing the two prediction pages, so when you are ready, please continue to the prediction pages.

Prediction Page 1:

Please complete three coin tosses now and click on the number of correct coin toss predictions. If this is the task selected for you, we will add the amount listed to the donation to the Republican National Party.

$\begin{array}{ll}0 & 0 \text { correct prediction - Earn } \$ 0 \text { for the Republican National Party (1) } \\ & 1 \text { correct prediction - Earn } \$ 0 \text { for the Republican National Party (2) } \\ & 2 \text { correct predictions - Earn } \$ 1 \text { for the Republican National Party (3) } \\ & 3 \text { correct predictions - Earn } \$ 8 \text { for the Republican National Party (4) }\end{array}$


Prediction Page 2:

Please complete three coin tosses now and click on the number of correct coin toss predictions. If this is the task selected for you, we will add the amount listed to the donation to the Republican National Party.

$\begin{array}{ll}0 & 0 \text { correct prediction - Earn } \$ 0 \text { for the Republican National Party (1) } \\ & 1 \text { correct prediction - Earn } \$ 1 \text { for the Republican National Party (2) } \\ 0 & 2 \text { correct predictions - Earn } \$ 8 \text { for the Republican National Party (3) } \\ 0 & 3 \text { correct predictions - Earn } \$ 8 \text { for the Republican National Party (4) }\end{array}$

Decision Task 1 (Republican National Party):

If this page is randomly selected, based on your choice below we will either add or subtract money from the donation to be made at the end of the study to the Republican National Party.

O Add $\$ 2$ to the total donation to the Republican National Party (1)

O Add nothing to the total donation to the Republican National Party (2)

O Subtract $\$ 2$ from the total donation to the Republican National Party (3)

Decision Task 2 (Democratic National Party):

If this page is randomly selected, based on your choice below we will either add or subtract money from the donation to be made at the end of the study to the Democratic National Party.

Add $\$ 2$ to the total donation to the Democratic National Party (1)

Add nothing to the total donation to the Democratic National Party (2)

Subtract $\$ 2$ from the total donation to the Democratic National Party (3)

Before we move on to the attitude and demographic questions, we would like to give you one more chance to earn more money for yourself. Like you, other participants in this study are reporting the outcomes of coin tosses to earn money for a political party. We would like you to evaluate whether reporting more (or less) money earned than actually occurred is "socially appropriate" and "consistent with moral or proper social behavior," or are "socially inappropriate" and "inconsistent with moral or proper social behavior." By socially appropriate, we mean behavior that most people agree is the "correct" or "ethical" thing to do. Another way to think about what we mean is that if the participant was to select a socially inappropriate choice, then someone else might be judgmental of this person for doing so. Please answer each question as accurately as possible, based on your opinion of what constitutes socially appropriate or socially inappropriate behavior. At the end of the experiment, we will randomly select one participant and one of the four questions below. If you are chosen and gave the same response to the question that is most frequently given by all other participants, then you will receive an additional $\$ 100$ as a bonus to your MTurk account. 
How socially appropriate or inappropriate is it to report...

\begin{tabular}{|l|c|c|c|c|} 
& $\begin{array}{c}\text { Very Socially } \\
\text { Inappropriate } \\
(1)\end{array}$ & $\begin{array}{c}\text { Somewhat } \\
\text { Socially } \\
\text { Inappropriate } \\
(2)\end{array}$ & $\begin{array}{c}\text { Somewhat } \\
\text { Socially } \\
\text { Appropriate } \\
(3)\end{array}$ & $\begin{array}{c}\text { Very } \\
\text { Socially } \\
\text { Appropriate } \\
\text { (4) }\end{array}$ \\
\hline $\begin{array}{l}\text { an outcome that earns } \$ 0 \text { for a political } \\
\text { party you strongly support when the } \\
\text { prediction would earn } \$ 0(4)\end{array}$ & 0 & 0 & 0 & 0 \\
$\begin{array}{l}\text { an outcome that earns } \$ 8 \text { for a political } \\
\text { party you strongly support when the } \\
\text { prediction would earn } \$ 0(1)\end{array}$ & 0 & 0 & 0 & 0 \\
$\begin{array}{l}\text { an outcome that earns } \$ 8 \text { for a political } \\
\text { party you strongly oppose when the } \\
\text { prediction would earn } \$ 8(2)\end{array}$ & 0 & 0 & 0 & 0 \\
$\begin{array}{l}\text { an outcome that earns } \$ 0 \text { for a political } \\
\text { party you strongly oppose when the } \\
\text { prediction would earn } \$ 8(3)\end{array}$ & 0 & 0 & 0 & 0 \\
\hline
\end{tabular}

Before we finish, please complete the following set of questions about you experience, your views and yourself.

What type of coin did you use for the coin toss?

$\begin{array}{ll}\bigcirc & \text { Quarter (1) } \\ \bigcirc & \text { Dime (2) } \\ \bigcirc & \text { Nickel (3) } \\ \bigcirc & \text { Penny (4) } \\ \bigcirc & \text { Other (5) }\end{array}$

What organization were you partnered with for the coin toss donations?

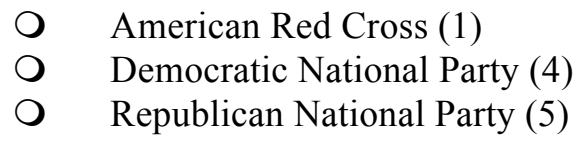

How many sets of coin tosses did you complete?

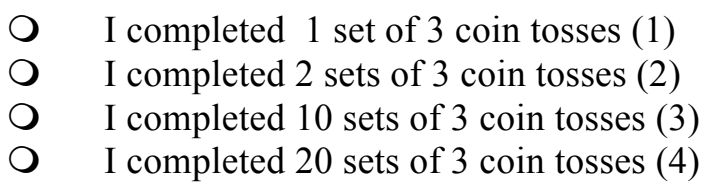

How will the amount of your donation determined?

The sum of the outcomes from all four tasks will be added together (1)

One of the four pages will be randomly chosen and the outcome from that page will be used.

(2)

The political party will be given a set amount of money regardless of what I did. (5) 
We would like to know more about your political ideology. Please indicate how much you identify yourself as being politically liberal or conservative in general.

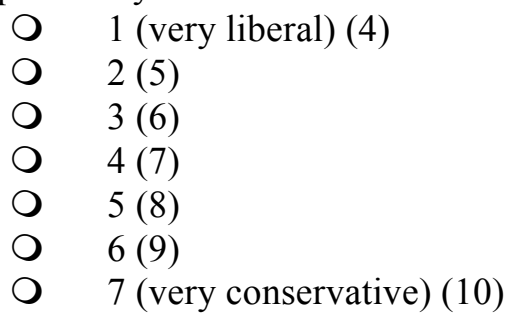

Please indicate how much you identify yourself as being politically liberal or conservative in economic issues

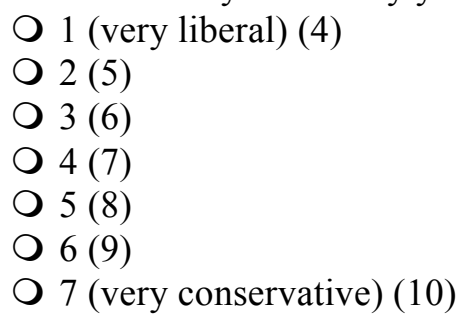

Please indicate how much you identify yourself as being politically liberal or conservative on social issues.

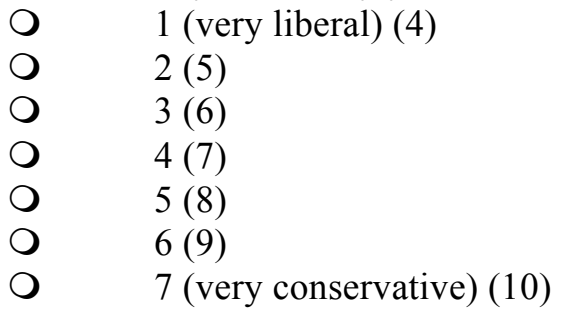

How would you classify your political affiliation?

$\begin{array}{ll}\text { O } & \text { Republican (1) } \\ \bigcirc & \text { Democratic (2) } \\ 0 & \text { Independent (3) } \\ 0 & \text { Other (4) }\end{array}$

How often do you vote in national elections (including Senate, House of Representative, and Presidential elections)?

I never vote in national elections (1)

I occasionally vote in national elections (2)

I sometimes vote in national elections (3)

O I frequently vote in national elections (6)

O I usually vote in national elections (4)

I I always vote in national elections (5) 
Please indicate your level of agreement with the following statements $(1=$ Strongly disagree, $7=$ Strongly agree).

\begin{tabular}{|c|c|c|c|c|c|c|c|}
\hline & $\begin{array}{l}\text { Strongly } \\
\text { disagree } \\
\text { (1) }\end{array}$ & $\begin{array}{l}\text { Disagree } \\
(2)\end{array}$ & $\begin{array}{l}\text { Somewhat } \\
\text { disagree (3) }\end{array}$ & $\begin{array}{l}\text { Neither } \\
\text { agree nor } \\
\text { disagree } \\
\text { (4) }\end{array}$ & $\begin{array}{l}\text { Somewhat } \\
\text { agree (5) }\end{array}$ & $\begin{array}{l}\text { Agree } \\
\text { (6) }\end{array}$ & $\begin{array}{l}\text { Strongly } \\
\text { agree (7) }\end{array}$ \\
\hline $\begin{array}{l}\text { Luck plays an important part in } \\
\text { everyone's life. (1) }\end{array}$ & $\mathrm{O}$ & $\mathrm{O}$ & $\mathrm{O}$ & $\mathrm{O}$ & $\mathrm{O}$ & $\mathrm{O}$ & O \\
\hline $\begin{array}{l}\text { Some people are consistently lucky, and } \\
\text { others are unlucky. (2) }\end{array}$ & $\mathrm{O}$ & $\mathrm{O}$ & $\mathrm{O}$ & $\mathrm{O}$ & $\mathrm{O}$ & $\mathrm{O}$ & $\mathrm{O}$ \\
\hline $\begin{array}{l}\text { I consider myself to be a lucky person. } \\
\text { (3) }\end{array}$ & $\mathrm{O}$ & $\mathrm{O}$ & $\mathrm{O}$ & $\mathrm{O}$ & $\mathrm{O}$ & $\mathrm{O}$ & $\mathrm{O}$ \\
\hline I believe in luck. (4) & O & $\mathrm{O}$ & $\mathrm{O}$ & $\mathrm{O}$ & $\mathrm{O}$ & $\mathrm{O}$ & O \\
\hline I often feel like it's my lucky day. (5) & $\mathrm{O}$ & $\mathrm{O}$ & $\mathrm{O}$ & $\mathrm{O}$ & $\mathrm{O}$ & $\mathrm{O}$ & $\mathrm{O}$ \\
\hline I consistently have good luck. (6) & $\mathrm{O}$ & $\mathrm{O}$ & $\mathrm{O}$ & $\mathrm{O}$ & $\mathrm{O}$ & $\mathrm{O}$ & O \\
\hline $\begin{array}{l}\text { It's a mistake to base any decisions on } \\
\text { how lucky you feel. ( } 7 \text { ) }\end{array}$ & $\mathrm{O}$ & $\mathrm{O}$ & $\mathrm{O}$ & $\mathrm{O}$ & $\mathrm{O}$ & $\mathrm{O}$ & $\mathrm{O}$ \\
\hline Luck works in my favor. (8) & O & $\mathrm{O}$ & $\mathrm{O}$ & $\mathrm{O}$ & $\mathrm{O}$ & $\mathrm{O}$ & $\mathrm{O}$ \\
\hline $\begin{array}{l}\text { I don't mind leaving things to chance } \\
\text { because I'm a lucky person. (9) }\end{array}$ & $\mathrm{O}$ & 0 & 0 & 0 & 0 & 0 & 0 \\
\hline $\begin{array}{l}\text { Even the things in life I can't control } \\
\text { tend to go my way because I'm lucky. } \\
\text { (10) }\end{array}$ & 0 & 0 & 0 & 0 & 0 & O & 0 \\
\hline $\begin{array}{l}\text { There is such a thing as luck that favors } \\
\text { some people, but not others. (11) }\end{array}$ & O & 0 & 0 & 0 & 0 & 0 & 0 \\
\hline $\begin{array}{l}\text { Luck is nothing more than random } \\
\text { chance. (12) }\end{array}$ & 0 & 0 & 0 & 0 & 0 & 0 & 0 \\
\hline
\end{tabular}

In this set of questions you will read about situations that people are likely to encounter in day-today life, followed by common reactions to those situations. As you read each scenario, try to 
imagine yourself in that situation. Then indicate the likelihood that you would react in the way described.

\begin{tabular}{|c|c|c|c|c|c|c|c|}
\hline & $\begin{array}{l}\text { very } \\
\text { unlikely } \\
\text { (1) }\end{array}$ & $\begin{array}{l}\text { unlikely } \\
\text { (2) }\end{array}$ & $\begin{array}{l}\text { slightly } \\
\text { unlikely } \\
\text { (3) }\end{array}$ & $\begin{array}{l}\text { about } \\
50 \% \\
\text { likely } \\
(4)\end{array}$ & $\begin{array}{l}\text { slightly } \\
\text { likely } \\
(5)\end{array}$ & $\begin{array}{l}\text { likely } \\
\text { (6) }\end{array}$ & $\begin{array}{l}\text { very } \\
\text { likely } \\
(7)\end{array}$ \\
\hline $\begin{array}{l}\text { After realizing you have received too much } \\
\text { change at a store, you decide to keep it because } \\
\text { the salesclerk doesn't notice. What is the } \\
\text { likelihood that you would feel uncomfortable } \\
\text { about keeping the money? (1) }\end{array}$ & 0 & 0 & 0 & 0 & 0 & $\mathrm{O}$ & O \\
\hline $\begin{array}{l}\text { You give a bad presentation at work. Afterwards } \\
\text { your boss tells your coworkers it was your fault } \\
\text { that your company lost the contract. What is the } \\
\text { likelihood that you would feel incompetent? (2) }\end{array}$ & 0 & 0 & 0 & 0 & 0 & 0 & 0 \\
\hline $\begin{array}{l}\text { At a coworker's party, you spill red wine on their } \\
\text { new cream colored carpet. You cover the stain } \\
\text { with a chair so that nobody notices. What is the } \\
\text { likelihood that you would feel that the way you } \\
\text { acted was pathetic? (3) }\end{array}$ & 0 & 0 & 0 & 0 & 0 & 0 & 0 \\
\hline $\begin{array}{l}\text { You lie to people but they never find out about it. } \\
\text { What is the likelihood that you would feel } \\
\text { terrible about the lies you told? (4) }\end{array}$ & O & 0 & 0 & 0 & 0 & 0 & 0 \\
\hline $\begin{array}{l}\text { You successfully exaggerate your damages in a } \\
\text { lawsuit. Months later, your lies are discovered } \\
\text { and you are charged with perjury. What is the } \\
\text { likelihood that you would think you are a } \\
\text { despicable human being? (5) }\end{array}$ & 0 & 0 & 0 & 0 & 0 & 0 & 0 \\
\hline $\begin{array}{l}\text { You make a mistake at work and find out a } \\
\text { coworker is blamed for the error. Later, your } \\
\text { coworker confronts you about your mistake. } \\
\text { What is the likelihood that you would feel like a } \\
\text { coward? (6) }\end{array}$ & O & 0 & 0 & 0 & 0 & 0 & 0 \\
\hline
\end{tabular}

Please answer regarding your frequency of the following:

\begin{tabular}{|c|c|c|c|c|c|}
\hline & $\begin{array}{l}\text { never } \\
\text { (1) }\end{array}$ & $\begin{array}{l}\text { rarely } \\
\text { (2) }\end{array}$ & $\begin{array}{l}\text { occasionally } \\
\text { (3) }\end{array}$ & $\begin{array}{l}\text { often } \\
(4)\end{array}$ & $\begin{array}{l}\text { very } \\
\text { often } \\
(5)\end{array}$ \\
\hline How often do you think about religious issues? (1) & O & $\mathrm{O}$ & $\mathrm{O}$ & O & $\mathrm{O}$ \\
\hline $\begin{array}{l}\text { How often do you experience situations in which you have } \\
\text { the feeling that God or something divine intervenes in } \\
\text { your life? (2) }\end{array}$ & $\mathrm{O}$ & $\mathrm{O}$ & $\mathrm{O}$ & O & O \\
\hline How often do you take part in religious services? (3) & O & $\mathrm{O}$ & $\mathrm{O}$ & $\mathrm{O}$ & $\mathrm{O}$ \\
\hline How often do you pray? (4) & $\mathrm{O}$ & $\mathrm{O}$ & $\mathrm{O}$ & $\mathrm{O}$ & $\mathrm{O}$ \\
\hline
\end{tabular}


To what extent do you believe that God or something divine exists?

$$
\begin{array}{ll}
\text { not at all (1) } \\
\text { not very much (2) } \\
\text { moderately (3) } \\
\bigcirc & \text { quite a bit (4) } \\
\bigcirc & \text { very much so (5) }
\end{array}
$$

And finally a few questions about yourself... What is your gender?

$$
\begin{array}{ll}
\bigcirc & \text { Male (1) } \\
\bigcirc & \text { Female (2) }
\end{array}
$$

What is your highest educational degree obtained?
O Primary school (1)
Less than high school (2)
High school diploma or equivalent (3)
Undergraduate degree (4)
Post-graduate degree (5)

What year were you born (e.g., 1980) (Drop Down)

What is your approximate household annual pretax income?
Less than $\$ 10,000$ (1)
Between $\$ 10,000$ and $\$ 20,000$ (2)
O Between $\$ 20,000$ and $\$ 30,000$ (3)
Between $\$ 30,000$ and $\$ 50,000$ (4)
Between $\$ 50,000$ and $\$ 70,000(5)$
Between $\$ 70,000$ and $\$ 90,000$ (6)
Between $\$ 90,000$ and $\$ 110,000(7)$
Between $\$ 110,000$ and $\$ 130,000(8)$
O Between $\$ 130,000$ and $\$ 150,000(9)$
More than $\$ 150,000(10)$

How much money do you spend in a typical week (this should be your daily expenses e.g., food, travel, mobile charges, purchases; but excluding rent, mortgage, educational fees, work expenses)?
O $\$ 0-\$ 29(1)$
O $\$ 30-\$ 49(2)$
O $\$ 50-\$ 79(3)$
O $\$ 80-\$ 119(4)$
O $\$ 120-\$ 174(5)$
○ $\$ 175-\$ 249(6)$
O $\$ 250-\$ 350$ (7)
O More than $\$ 350$ (8) 
In the last four years, how many times have you donated money to a political party?

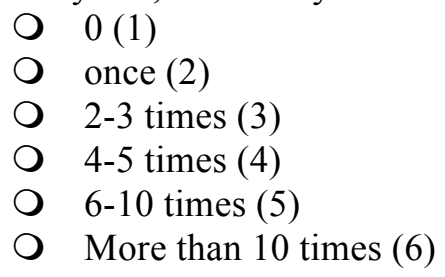

In the last four years, how much money have you donated to a political party?

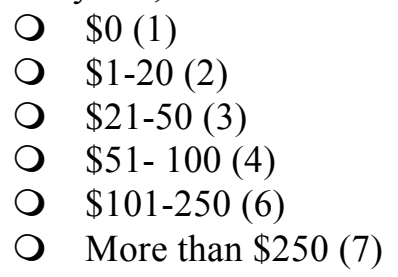

In the last four years, how many times have you donated your time to a political party?

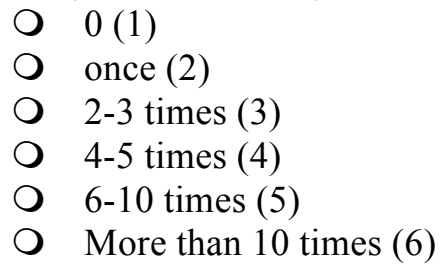

In the last four years, how much time have you donated to a political party?

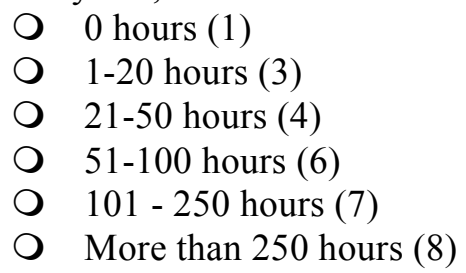

What do you think we are trying to assess with this study? (open-ended) 


\section{Appendix Table A1. List of studies included in the review}

\begin{tabular}{|c|c|c|c|c|c|c|c|c|}
\hline Authors (Year) & $\begin{array}{c}\mathrm{Nb} \\
\text { treatments }\end{array}$ & $\begin{array}{c}\mathrm{Nb} \\
\text { subjects }\end{array}$ & Country & Lab & Students & $\begin{array}{c}\mathrm{Nb} \text { coin } \\
\text { tosses }\end{array}$ & $\begin{array}{c}\mathrm{Nb} \text { die } \\
\text { rolls }\end{array}$ & $\begin{array}{l}\mathrm{Nb} \text { other } \\
\text { devices }\end{array}$ \\
\hline 1. Abeler et al. (2014) & 4 & 1102 & Germany & Lab+telephone & Both & 1 and 4 & - & - \\
\hline 2. Abeler (2015) & 1 & 60 & China & Lab & Yes & - & - & 1 ticket/1। \\
\hline 3. Abeler et al. (2016) & 8 & 1098 & UK & Lab & Yes & - & - & 1 chip/ $5 \mathrm{C}$ \\
\hline 4. Amir et al. (2016) & 11 & 403 & Israel & Online & Yes & 20 & - & - \\
\hline 5. Anthony et al. (2016) & 2 & 200 & Germany & Lab & Yes & - & 1 & - \\
\hline 6. Arbel et al. (2014) & 2 & 399 & Israel & Lab & Yes & - & 1 & - \\
\hline 7. Ariely et al. (2014) & 2 & 188 & Germany & Art. field & No & - & 40 & - \\
\hline 8. Aydogan et al. (2015) & 2 & 120 & Germany & Lab & Yes & 2 & - & - \\
\hline 9. Banerjec et al. (2016) & 8 & 1344 & India & Art. field & No & - & 1 & - \\
\hline 10. Barfort et al. (2015) & 1 & 862 & Denmark & Online & Yes & - & $4 * 10$ & - \\
\hline 11. Beck et al. (2016) & 6 & 191 & Germany & Lab & Yes & - & 1 & - \\
\hline 12. Blanco et al. (2015) & 2 & 173 & Spain & Lab & Yes & - & 1 & \\
\hline 13. Blanco and Cardenas (2015) & 2 & 103 & Colombia & Lab & Yes & - & 1 & - \\
\hline 14. Braun and Hornuf (2015) & 7 & 342 & Germany & Lab & Yes & - & 40 & - \\
\hline 15. Bryan et al. (2013) & 7 & 238 & USA & Lab + online & Both & 10 & - & $1 \mathrm{nb} / 10$ \\
\hline 16. Bucciol and Piovesan (2011) & 2 & 160 & Italy & Art. field & No & 1 & - & - \\
\hline 17. Cadsby et al. (2016) & 1 & 90 & China & Lab & Yes & - & 1 & - \\
\hline 18. Chylitova and Korbel (2014) & 3 & 444 & Czech Rep. & Art. field & Yes & - & 1 & - \\
\hline 19. Clot et al. (2014) & 2 & 98 & Madagascar & Lab & Yes & - & 1 & - \\
\hline 20. Cohn et al. (2014) & 8 & 435 & Switzerland & Art.field+ online & Both & 10 & - & - \\
\hline 21. Cohn and Marechal (2015) & 1 & 162 & Switzerland & Art. field & No & 10 & - & - \\
\hline 22. Cohn et al. (2015) & 4 & 285 & Switzerland & Art. field & No & 10 & - & - \\
\hline 23. Conrads et al. (2013) & 4 & 554 & Germany & Lab & Yes & - & 1 & - \\
\hline 24. Conrads (2014) & 4 & 246 & Germany & $\mathrm{Lab}+$ tel + online & Yes & 4 & - & - \\
\hline 25. Dai et al. (2016) & 2 & 471 & France & Art. ficld + lab & Both & - & $1 ; 3$-sided & - \\
\hline 26. Dato and Nieken (2015) & 1 & 288 & Germany & $\mathrm{Lab}$ & Yes & - & 1 & - \\
\hline 27. Dieckmann et al. (2015) & 5 & 1015 & Multiple & Online & No & 1 & - & - \\
\hline 28. Dickmann et al. (2015) & 6 & 466 & Switzerland & Lab & Yes & - & 1 & - \\
\hline 29. Di Falco et al. (2016) & 1 & 1080 & Tanzania & Lab & Yes & 1 & - & - \\
\hline 30. Djawadi and Fahr (2015) & 1 & 252 & Germany & Art. Field & Both & - & - & 1 chip \\
\hline 31. Drupp et al. (2016) & 4 & 164 & Germany & Mail & Both & 4 & - & - \\
\hline 32. Effron et al. (2015) & 6 & 1704 & USA & Online & No & 13 and 20 & - & - \\
\hline 33. Fischbacher and Föllmi-Heusi (2013) & 7 & 1347 & Switzerland & Lab & Yes & - & 1 & - \\
\hline 34. Foerster et al. (2013) & 2 & 28 & Germany & Lab & Yes & - & $6 ; 8$-sided & - \\
\hline 35. Fosgaard et al. (2013) & 4 & 209 & Denmark & Lab & Yes & 1 & - & - \\
\hline 36. Gächter and Schultz (2016) & 23 & 2568 & Multiple & Lab & Yes & - & 1 & - \\
\hline 37. Halevy et al. (2013) & 1 & 51 & Netherlands & Lab & Yes & - & 60 & - \\
\hline
\end{tabular}




\begin{tabular}{|c|c|c|c|c|c|c|c|c|}
\hline Authors (Year) & $\begin{array}{c}\mathrm{Nb} \\
\text { treatments }\end{array}$ & $\begin{array}{c}\mathrm{Nb} \\
\text { subjects }\end{array}$ & Country & Lab & Students & $\begin{array}{c}\mathrm{Nb} \text { coin } \\
\text { tosses }\end{array}$ & $\begin{array}{l}\mathrm{Nb} \text { die } \\
\text { rolls }\end{array}$ & $\begin{array}{l}\text { Nb other } \\
\text { devices }\end{array}$ \\
\hline 38. Hanna and Wang (2013) & 2 & 826 & India & Art. field +lab & Both & - & 42 & - \\
\hline 39. Hilbig and Hessler (2013) & 6 & 765 & Germany & Lab & Yes & - & 1 & - \\
\hline 40. Hilbig and Zettler (2015) & 6 & 549 & Germany & Lab+Online & No & 2 and 10 & 1 & - \\
\hline 41. Houser et al. (2016) & 4 & 249 & USA & Art. field & No & 2 & - & - \\
\hline 42. Hruschka et al. (2014) & 8 & 223 & Multiple & Art. field & No & 30 & - & - \\
\hline 43. Hugh-Jones (2016) & 30 & 1475 & Multiple & On line & No & 1 & - & - \\
\hline 44. Jacobsen and Piovesan (2016) & 3 & 149 & Denmark & Art. field & No & - & 1 & - \\
\hline 45. Jiang (2013) & 2 & 39 & Netherlands & Lab & Yes & - & 20 & - \\
\hline 46. Jiang (2015) & 4 & 216 & Multiple & Lab & Yes & - & 20 & - \\
\hline 47. Kajakaite and Gneezy (2015) & 17 & 1303 & USA, Germ & Lab & Yes & - & 1 & 1 ticket/10 \\
\hline 48. Kroher and Wolbring (2015) & 6 & 382 & Germany & Lab + online & Yes & - & 1 & - \\
\hline 49. Mann et al. (2016) & 10 & 2179 & Multiple & Art. field + lab & Both & - & 20 & - \\
\hline 50. Meub et al. (2015) & 2 & 94 & Germany & Lab & Yes & - & 1 & - \\
\hline 51. Muehlheusser et al. (2015) & 1 & 108 & Germany & Lab & Yes & - & 1 & - \\
\hline 52. Munoz-Izquierdo et al. (2014) & 3 & 270 & Spain & Art. field & Yes & 1 & - & - \\
\hline 53. Pascual-Ezama et al. (2015) & 48 & 1440 & Multiple & $\begin{array}{c}\text { Lab+verbal }+ \text { no } \\
\text { contact }\end{array}$ & Yes & 1 & - & - \\
\hline 54. Ploner and Regner (2013) & 6 & 316 & Germany & Lab & Yes & - & 1 & - \\
\hline 55. Potters and Stoop (2016) & 2 & 102 & Netherlands & Lab & Yes & - & - & 20 cards \\
\hline 56. Rauhut (2013) & 3 & 240 & Switzerland & Lab & Yes & - & $4 * 12$ & - \\
\hline 57. Ruffle and Tobol (2014) & 1 & 427 & Israel & Art. field & No & - & 1 & - \\
\hline 58. Ruffle and Tobol (2015) & 1 & 156 & Israel & Art. field & No & - & $i$ & - \\
\hline 59. Schindler and Pfattheicher & 4 & 386 & Multiple & Labtonline & Both & 1 & 75 & - \\
\hline 60. Shalvi (2012) & 2 & 178 & Netherlands & Lab & Yes & 20 & - & - \\
\hline 61. Shalvi et al. (2011) & 2 & 129 & USA & Lab & Yes & - & 1 & - \\
\hline 62. Shalvi et al. (2012) & 4 & 144 & Israel & Lab & Yes & - & 1 & - \\
\hline 63. Shalvi and Leiser (2013) & 2 & 126 & Israel & Lab & Yes & - & 1 & - \\
\hline 64. Shalvi and de Dreu (2014) & 8 & 120 & Netherlands & Lab & Yes & 10 & - & - \\
\hline 65. Shen et al. (2016) & 1 & 205 & Singapore & Lab & Yes & - & 1 & - \\
\hline 66. Skoda (2013) & 3 & 90 & Czech Rep. & Lab & Yes & - & 1 & - \\
\hline 67. Suri et al. (2011) & 3 & 674 & India, USA & Online & No & - & 1 & - \\
\hline 68. Thielmann et al. (2016) & 1 & 152 & Germany & Online & No & 2 & - & - \\
\hline 69. Utikal and Fischbacher (2013) & 2 & 31 & Germany & Art. field + lab & Both & - & 1 & - \\
\hline 70. Waubert de Puiseau and Glöckner (2012) & 4 & 407 & Germany & Online & Both & 5 & - & - \\
\hline 71. Weisel and Shalvi (2015) & 1 & 36 & Germany & Lab & Yes & - & 20 & - \\
\hline 72. Wibral et al. (2012) & 2 & 91 & Germany & Lab & Yes & - & 1 & - \\
\hline 73. Zetler et al. (2015) & 1 & 134 & Germany & Online & No & 2 & - & - \\
\hline 74. Zimerman et al. (2014) & 1 & 189 & Israel & Online & Yes & 20 & - & - \\
\hline Total & 363 & 33540 & 44 & $53 \%$ of treatments & $\begin{array}{c}68.5 \% \text { of } \\
\text { treatments }\end{array}$ & $\begin{array}{c}49 \% \text { of } \\
\text { treatments }\end{array}$ & $\begin{array}{c}47 \% \text { of } \\
\text { treatments }\end{array}$ & $\begin{array}{c}4 \% \text { of } \\
\text { treatments }\end{array}$ \\
\hline
\end{tabular}




\section{Appendix Table A2. Exogenous characteristics of participants}

\begin{tabular}{|c|c|c|c|c|c|}
\hline \multirow[t]{2}{*}{ Experimental treatments } & \multicolumn{3}{|c|}{ Study 1: Lying for oneself } & \multicolumn{2}{|c|}{ Study 2: Lying for a cause ${ }^{\text {a }}$} \\
\hline & 0002 & 0022 & 0222 & Supporting & Opposing \\
\hline $\mathrm{N}$ & 80 & 327 & 571 & 115 & 146 \\
\hline$\%$ Females & 57.5 & 48.3 & 52.7 & 45.2 & 42.5 \\
\hline Mean (SD) age & $36(11.7)$ & $38(12.0)$ & $38(12.1)$ & $35(10.6)$ & $38(11.3)$ \\
\hline \multicolumn{6}{|l|}{ Education (in \%) } \\
\hline - Less high school & 0 & .6 & .5 & .9 & .7 \\
\hline - High school & 28.7 & 29.2 & 31.0 & 39.1 & 39.3 \\
\hline - Undergraduate & 58.8 & 57.1 & 49.5 & 50.4 & 49.7 \\
\hline - Post-graduate & 12.5 & 13.2 & 19.0 & 9.6 & 10.3 \\
\hline \multicolumn{6}{|l|}{ Income (in \%) } \\
\hline$<\$ 30 \mathrm{k}$ & 35.0 & 24.6 & 25.9 & 33.9 & 31.3 \\
\hline$\$ 30 \mathrm{k}-\$ 50 \mathrm{k}$ & 16.3 & 26.5 & 24.3 & 27.8 & 20.1 \\
\hline$\$ 50 \mathrm{k}-\$ 70 \mathrm{k}$ & 12.5 & 22.1 & 21.0 & 16.5 & 18.1 \\
\hline$\$ 70 \mathrm{k}-\$ 90 \mathrm{k}$ & 15.0 & 10.4 & 10.7 & 7.8 & 11.1 \\
\hline$>\$ 90 \mathrm{k}$ & 21.2 & 16.4 & 18.1 & 13.9 & 19.4 \\
\hline \multicolumn{6}{|l|}{ Spending (in \%) } \\
\hline$<\$ 50$ & 15.0 & 15.7 & 16.1 & 20.8 & 10.3 \\
\hline$\$ 50-\$ 79$ & 15.0 & 13.8 & 11.5 & 19.1 & 14.5 \\
\hline$\$ 80-\$ 119$ & 23.8 & 21.3 & 23.3 & 14.8 & 21.4 \\
\hline$\$ 120-\$ 174$ & 15.0 & 20.7 & 19.3 & 20.9 & 20.7 \\
\hline$\$ 175-\$ 249$ & 15.0 & 13.5 & 14.0 & 18.3 & 14.5 \\
\hline$>\$ 250$ & 16.3 & 15.1 & 15.9 & 10.5 & 18.6 \\
\hline \multicolumn{6}{|l|}{ Affiliation (in \%): } \\
\hline - DNP & & & & 72.2 & 67.1 \\
\hline - RNP & & & & 27.8 & 32.9 \\
\hline \multicolumn{6}{|l|}{ Agreement w/ goals } \\
\hline of party donating to & & & & & \\
\hline Dem - Dems(s)/Reps(o) & & & & $33.1(13.7)$ & $-32.5(20.0)$ \\
\hline $\operatorname{Rep}-\operatorname{Reps}(\mathrm{s}) / \operatorname{Dems}(\mathrm{o})$ & & & & $27.9(16.6)$ & $-29.3(19.2)$ \\
\hline
\end{tabular}

Notes: DNP: Democratic National Party; RNP: Republican National Party. "Income" is percentage of people in income categories. "Spending" is percentage of people in weekly spending categories. "Affiliation" percentage of people state either Democratic or Republican affiliation. "Agree with goals" is the mean response to the question about how much the subject agrees with the goals of the party they were assigned to donate to, on a continuous scale between -50 and +50 (included); for example, how much did a Democrat assigned to donate to the DNP agree with the goals of the DNP (support), or how much did a Democrat assigned to donate to the RNP agree with the goals of the RNP (oppose). ${ }^{\text {a }}$ Only people who stated their party affiliation as Democrat or Republican are included since these allow for matching or mismatching.

The various demographics are randomly dispersed across the conditions. In study 1, pairwise testing show no significant differences between conditions on gender ( $\mathrm{ps}>0.14)$, age ( $\mathrm{ps}>0.14)$, education $(\mathrm{ps}>0.90)$, income $(p$ $>0.07$ ), or weekly spending ( $p$ s $>0.80$ ). In study 2 , there are no significant differences between conditions on gender $(p>0.69)$, age $(p>0.05)$, education $(p>0.90)$, income $(p>0.46)$, weekly spending $(p>0.34)$, political affiliation $(p>0.38)$. As expected, there is a significant difference between agreement with the political goals of the party the participant is donating to, based on whether the person was in the support or oppose condition ( $p s<$ $0.001)$. 
Appendix Table A3:

Study 1 Logistic Regression: Influence of Possible Covariates on Payout

\begin{tabular}{lcccc} 
DV: Participant Payout & \multicolumn{4}{c}{ Study 1: Lying for oneself } \\
\cline { 2 - 5 } Beta(SE) & Overall & 0002 & 0022 & 0222 \\
\cline { 2 - 5 } $\mathrm{N}$ & 927 & 78 & 304 & 545 \\
\hline Females & $0.020(0.21)$ & $0.387(0.51)$ & $-0.120(0.33)$ & $-0.304(0.52)$ \\
Year born & $0.027(0.01)^{* * *}$ & $0.048(0.02)^{* *}$ & $0.037(0.01)^{* * *}$ & $0.037(0.02)^{* *}$ \\
Education & $-0.242(0.15)$ & $-0.601(0.43)$ & $0.640(0.26)^{* *}$ & $0.389(0.38)$ \\
Income & $0.094(0.06)$ & $0.060(0.14)$ & $0.229(0.10)^{* *}$ & $0.029(0.14)$ \\
Spending & $0.000(0.06)$ & $-0.159(0.18)$ & $0.023(0.10)$ & $0.092(0.15)$ \\
Luck Beliefs & & & & \\
$\quad$ - Luck exists & $0.021(0.09)$ & $0.079(0.25)$ & $-0.019(0.13)$ & $0.149(0.20)$ \\
- I am lucky & $0.002(0.10)$ & $0.290(0.25)$ & $0.143(0.14)$ & $0.216(0.27)$ \\
\hline
\end{tabular}

Notes: The current technique does not allow for regression-based analysis, so to test the effects of covariates we have used the participant's payout level as a proxy for lying, since those who lied will have gotten the larger pays. "Income" is percentage of people in income categories. "Spending" is percentage of people in weekly spending categories. Factor analysis of the belief in luck scale (Darke and Freedman 1997) forms two factors representing a belief that there is such a thing as 'luck' and a belief that the respondent is lucky. ${ }^{* * *}$ and ** indicate significance at the 0.01 and 0.05 level, respectively. Note that the number of observations in this Table is slightly lower than the total number of participants since some subjects did not complete the demographic questionnaire.

As can be seen in Table A3, the demographic and attitudinal variables have little effect on the participant's payout. Only age consistently reaches the traditional significance cutoff in study 1 , such that younger people get higher payouts. Additional analyses (not shown) find no significant interactions of the covariates with the conditions (all $p$-values $>0.05$ ), demonstrating that none of the covariates moderate the effects of treatment on payout. 


\section{Appendix Table A4:}

\section{Study 2 Ordinal Logistic Regression: Influence of Possible Covariates on Payout}

\begin{tabular}{|c|c|c|c|c|c|c|}
\hline \multirow{3}{*}{$\begin{array}{l}\text { DV: } \\
\text { Participant } \\
\text { Payout } \\
\text { Beta(SE) } \\
\text { N }\end{array}$} & \multicolumn{3}{|c|}{ Study 2: 0018 Treatment } & \multicolumn{3}{|c|}{ Study 2: 0188 Treatment $^{\mathrm{a}}$} \\
\hline & Overall & Supporting & Opposing & \multirow{2}{*}{$\begin{array}{c}\text { Overall } \\
244\end{array}$} & Supporting & Opposing \\
\hline & 244 & 107 & 137 & & 107 & 137 \\
\hline Females & $0.103(0.26)$ & $0.088(0.40)$ & $0.335(0.38)$ & $0.109(0.27)$ & $0.121(0.49)$ & $-0.052(0.36)$ \\
\hline Year born & $-0.026(0.01)^{* *}$ & $-0.018(0.02)$ & $-0.043(0.02)^{* *}$ & $-0.015(0.01)$ & $-0.031(0.03)$ & $-0.032(0.02)$ \\
\hline Education & $-0.096(0.19)$ & $0.133(0.29)$ & $-0.280(0.27)$ & $-0.024(0.19)$ & $-0.206(0.36)$ & $0.067(0.25)$ \\
\hline Income & $0.120(0.07)$ & $0.182(0.11)$ & $0.092(0.10)$ & $-0.040(0.07)$ & $0.025(0.13)$ & $-0.074(0.09)$ \\
\hline Spending & $-0.058(0.08)$ & $-0.135(0.12)$ & $0.063(0.12)$ & $-0.049(0.08)$ & $-0.040(0.15)$ & $0.021(0.10)$ \\
\hline \multicolumn{7}{|l|}{ Luck Beliefs } \\
\hline - Luck exists & $-0.004(0.11)$ & $-0.203(0.15)$ & $0.175(0.17)$ & $0.138(0.11)$ & $-0.208(0.17)$ & $0.249(0.16)$ \\
\hline - I am lucky & $0.191(0.12)$ & $0.275(0.18)$ & $0.168(0.19)$ & $-0.057(0.13)$ & $0.365(0.21)$ & $-0.095(0.19)$ \\
\hline Religiosity & $-0.027(0.15)$ & $0.046(0.26)$ & $-0.139(0.21)$ & $0.232(0.15)$ & $0.060(0.31)$ & $0.190(0.19)$ \\
\hline Guilt Prone & $-0.390(0.14) * * *$ & $-0.512(0.21)^{* *}$ & $-0.086(0.20)$ & $-0.100(0.14)$ & $0.194(0.24)$ & $-0.057(0.19)$ \\
\hline Democratic & $-0.152(0.31)$ & $-0.459(0.51)$ & $0.050(0.41)$ & $-0.359(0.31)$ & $-0.617(0.60)$ & $-0.075(0.39)$ \\
\hline
\end{tabular}

Notes: The current technique does not allow for regression-based analysis, so to test the effects of covariates we have used the participant's payout level as a proxy for lying, since those who lied will have gotten the larger pays. "Income" is percentage of people in income categories. "Spending" is percentage of people in weekly spending categories. Factor analysis of the belief in luck scale (Darke and Freedman 1997) forms two factors representing a belief that there is such a thing as 'luck' and a belief that the respondent is lucky. Religiosity and guilt proneness are composite measure created from Huber and Huber's 5 item religiosity scale (2012) and Cohen et al's 6 item guilt proneness scale (2011), respectively. 'Democratic' tests whether Democrats get higher or lower payout than Republicans. ${ }^{a}$ Only people who stated their party affiliation as Democrat or Republican are included since these allow for matching or mismatching. . *** and ** indicate significance at the 0.01 and 0.05 level, respectively. Note that the number of observations in this Table is slightly lower than the total number of participants since some subjects did not complete the demographic questionnaire.

As can be seen in Table A4, the demographic and attitudinal variables have little effect on the participant's payout. We again see some effect of age, although less consistently strong here, and in the opposite direction as in study 1, with older respondents getting higher payouts. As in Study 1 Additional analyses (not shown) find no significant interactions of the covariates with the supporting and opposing conditions (all $p$-values $>0.05$ ), demonstrating that the covariates do not moderate the effects of treatment on payout. 